\title{
AN ANALYSIS OF INTERACTIVE LEARNING ENVIRONMENTS FOR ARITHMETIC AND ALGEBRA THROUGH AN INTEGRATIVE PERSPECTIVE
}

\author{
Jana Trgalova*, Denis Bouhineau**, Jean-François Nicaud** \\ * INRP, Lyon, France \\ ** Joseph Fourier University, Grenoble, France
}

\begin{abstract}
The analysis presented in this article tries to obtain a global view of the field of interactive learning environments (ILE) dedicated to arithmetic and algebra. As preliminaries, a brief overview of evaluation methods focusing on educational software is given and a short description of ten ILEs concerned by the study is provided as a kind of a state-of-the-art. Then the methodology of ILEs analysis developed in the TELMA project is explained consisting in the design and the refinement of an analysis grid and its use on the ten ILEs is mentioned. Next, a first level analysis of results leading to a compiled, analytic and synthetic view of the ILEs available and/or missing functionalities is given. A second level of the analysis is also proposed, with two concise representations of the ILEs, composed of graphical representations of the previous results, leading to a 3D map of ILEs dedicated to arithmetic and algebra. This map provides, as promised, a global view of the field and permits to define five sorts of ILEs according to two criteria: the first one is teacher-oriented and concerns usages enabled by the ILE; the second one is student-oriented and concerns control provided by the ILE to accomplish such usages.
\end{abstract}

Key words. Interactive learning environments (ILE), arithmetic, algebra, analysis of an ILE

\section{Introduction}

This paper is devoted to a study of Interactive Learning Environments (ILEs) in the field of arithmetic and algebra carried out within the framework of the TELMA project (Bottino \& Kynigos, this issue). Most of the TELMA teams are involved in the design and development of educational software, namely arithmetic, algebraic, dynamic geometrical and geometric-constructionist software, and all of them are interested in its use for the teaching and learning of mathematics. Getting a deeper insight to the landscape of state-of-the-art ILEs for mathematics became one of the objectives of the project. The aim of this study is not to judge the quality of the systems analysed, but rather to gain a global view 
of educational software for arithmetic and algebra, to identify and compare didactical functionalities (Cerulli et al. 2005, Artigue et al. this issue) of these systems in terms of available (or not available) features and functionalities.

Analysis of educational software is not a new issue and various methods have been proposed to study and evaluate computer-based learning environments. In section II, we give a brief overview of research studies dealing with analysis, evaluation and classification of learning environments. However, these studies concern usually the artefact only, and many issues of interest for TELMA teams, such as motivation of the designers, rationale for the design choices, difficulties encountered in the development process, remain hidden and unattainable by classical evaluation methods. Therefore, TELMA teams needed to develop a specific methodology enabling them to get light also on such implicit and obscure issues.

A methodological tool (section III), in the form of an analysis grid, has been designed to analytically describe interactive learning environments so that a better understanding is gained about all important issues in such environments. The tool aims at framing an analysis by inspection of the ILEs in order to gather as much information as possible not only about the artefacts, but also about their life cycles, starting from the design choices up to their experimentations and/or usages. The tool has been designed and improved through collaborative work between TELMA teams. The tool has been consequently applied to the analysis of ten existing ILEs for arithmetic and algebra: three ILEs developed by TELMA teams and seven ILEs developed outside TELMA (a brief presentation of these ILEs is provided in section IV). Two independent studies of the ILEs have been performed by two different TELMA teams and the results were compared and combined to obtain a unique analysis grid filled in for each ILE. A first analysis of the grids, done by the authors of this article, allowed comparing the ILEs based on features related to the knowledge domain, the user-ILE interaction and their technical aspects (section V). A second level of analysis is proposed in section VI, with two concise representations of the ILEs. They consist of graphical representations of the first level analysis results and lead to a 3D map of the studied ILEs providing a global view of the landscape of educational software for arithmetic and algebra. 


\section{A brief overview of the evaluation methods of educational software}

There seems to be a general agreement that evaluation of educational software is crucial and often constitutes an important phase of its development cycle (Nogry et al. 2004, Vivet 1996, Squires and Preece 1999, Senach 1993). Various methods for ILE evaluation are proposed in the literature. Tricot et al. (2003, p. 392) classify such methods according to two aspects:

(1) according to the way the evaluation is done, they distinguish between evaluation by inspection, which is performed by experts who use a set of predefined criteria to evaluate various aspects of the software, and empirical evaluation, which consists in observing users and interpreting their behaviours, attitudes and opinions. These two kinds of evaluation are obviously distinct and complementary.

(2) according to the moment when the evaluation is done, they distinguish between evaluation during the design phase, evaluation at the end of the design phase (validation), and a posteriori evaluation, i.e., when the system is not only designed but also realised.

Some authors suggest integrating the evaluation of the software from the very beginning of the design process (Nanard and Nanard 1998).

In order to clarify relationships between functionalities of an ILE, their interest for the user and the ease of their use, Senach (1993) considers two main dimensions in the ILE evaluation: (1) utility, which expresses the pedagogical efficiency of the ILE (does it allow achieving the specified educational goals?), and (2) usability, which evaluates the easiness of manipulating the ILE (is the ILE userfriendly, easy to use and reuse?). Tricot et al. (op. cit.) add a third dimension of the ILE to be taken into account in the evaluation process: its acceptability, which is related to the decision to use the software (is the ILE in accordance with the values, culture, and organisation of the institution where one wants to use it?). The authors provide sets of criteria allowing evaluation of an ILE from the points of view of utility, usability and acceptability, both by inspection and empirically.

While numerous research works deal with the issue of evaluation of educational software, a few propose concrete methods to evaluate its quality. Hû and Trigano (2000) have developed a method to evaluate interactive learning multimedia 
systems organised around six themes (see also Trigano and Giacomini-Pacurar 2004):

(1) General feeling (i.e., user's feelings about the use of the tool: active/passive, simple/complex, innovative/traditional, reassuring/confusing...);

(2) Technical quality (i.e., evaluation of the technical realisation: functioning, speed, installation, bugs...);

(3) Usability (i.e., ergonomic quality of the interface: manipulation, flexibility, homogeneity, adaptability...);

(4) Multimedia documents (i.e., quality and relevance of texts, sounds, images...);

(5) Scenario (i.e., quality of presentation and assembly of information: structure, browsing...);

(6) Pedagogical tools (i.e., pedagogical possibility of the software: quality and validity of content, variety and richness of activities offered by the tool, diagnosis tools, tutoring tools, hints...).

Evaluation of educational software for algebra is of special interest for TELMA teams. Nicaud (2001) elaborated a specific questionnaire to analyse ILEs for algebraic reasoning. He considers five categories of features:

(1) Domain/capacity of the ILE (e.g., extent of the domain covered by the ILE, power of the ILE in the domain, way of editing expressions...);

(2) Inference/interaction with the ILE (e.g., who selects the rule to be applied? who applies it? who selects the sub-expression?...);

(3) Adaptability of the ILE (e.g., possibility to activate/deactivate pieces of knowledge...);

(4) Heuristic feature of the ILE (e.g., is backtracking possible?...);

(5) Tutoring features of the ILE (e.g., nature of feedback or hints when provided...).

The above mentioned methods allow evaluating an artefact by inspecting its various functionalities and features, but they do not take into account issues related either to the design and development phase or to the usage of the artefact. These issues are of crucial interest for TELMA teams since, on the one hand, most of them are themselves involved in the development of educational software and learning about design and development issues related to similar systems may be an interesting and rewarding experience. On the other hand, information about actual or experimental usages of the system would be valuable in order to get a 
more complete picture of the artefact, gained both from the analysis by inspection and from results of empirical analyses.

Since the design and development of educational software bring together researchers and developers from different scientific fields, such as computer science, education, ergonomics, psychology, cognitive sciences, they need to face a multiplicity of points of view, which often results in deep misunderstandings and can thus turn to be a brake, rather than a catalyser of a fruitful cooperation among the disciplines. To cope with this diversity of approaches, Tchounikine et al. (2004) propose a set of dimensions for ILE analysis offering a framework for a better communication and mutual understanding. The authors specify that the framework concerns both the "ILE design project" and the "ILE" itself considered as a result of the design. The dimensions taken into account are organized into four groups:

[A] dimensions related to the definition of the research project, such as research aims, constraints on the ILE development, purpose of the artefact, actors involved in the design, social context of the research;

[B] dimensions related to the theoretical framework of the research, such as reference to the knowledge domain, theoretical frameworks specified, their role and the way they are used in the design;

[C] dimensions related to the results of the research, such as nature of the results, kind of their validation, their impact;

[D] dimensions related to the life cycle of the research, such as context of initiating the research, its history.

One of the authors of the present paper participated at the elaboration of the two above mentioned tools for ILE analysis, and has also been involved in the design of the methodological tool developed by TELMA teams. This tool, presented in the following section, draws on the above mentioned methods and criteria for evaluating educational software by inspection. Since the tool is aimed at studying specifically systems for teaching and learning arithmetic and algebra, the items of the grid are inspired by Nicaud's questionnaire (2001). Moreover, as suggested by Tchounikine et al. (2004) study, the tool takes into account the whole life cycle of the development of a system, starting from the aims of the design, through a detailed analysis of the artefact, up to the validation phase by means of empirical studies. 


\section{TELMA methodology for the ILEs analysis}

\section{III.1. Preliminary remarks}

Our study concerns educational software already in use or at least at the stage of an advanced prototype. Therefore, referring to Tricot et al. (2003) classification, the analysis TELMA teams carried out can be considered, as an a posteriori evaluation. Organizing conditions for an empirical evaluation of the selected systems was beyond the scope of the TELMA project, thus the analysis was done exclusively by inspection. Evaluation by inspection raises two fundamental issues. The one is linked to the fact that the knowledge of experts involved in the evaluation is individual, acquired by a professional practice, and is thus seldom made explicit (Senach 1990, p. 39). The other comes from the fact that an expert's evaluation is necessarily biased by focusing on aspects of the system relevant to her/his speciality and neglecting others (ibid.). An evaluation cannot be legitimate unless experts from different scientific domains are involved in it. To cope with these limits of the evaluation by inspection, a usual method consists of defining an evaluation grid providing a list as exhaustive as possible of features and aspects of the system to be evaluated. The first step in the TELMA study was therefore to define an analysis grid that would shape the inspection of the relevant aspects of the selected ILEs.

\section{III.2. Design of an analysis grid}

Recall that one of the main objectives of the TELMA project was to investigate the role theoretical frameworks play in the design both of educational software and of teaching experiments. Therefore, highlighting the theoretical background of the design of the ILEs was of particular interest for the TELMA study. Moreover, since some TELMA teams are involved in a process of design and development of educational artefacts, we supposed that considering the artefact as a result of a research project, and thus analysing not only the artefact itself but all possible aspects of its life cycle would be much more insightful with respect both to the research interests of the TELMA teams and to the purpose of our study. Therefore, Tchounikine's (2004) analysis framework seemed particularly relevant to our objectives. Since our study concerned educational software for arithmetic and algebra, most of the criteria from Nicaud's (2001) questionnaire were 
applicable to our study. Drawing on both above mentioned analysis frameworks, a specific methodological tool was elaborated through a collaborative work between TELMA teams. The initial version of the analysis grid was organized around three periods of life of an ILE (see Appendix 1).

- The Design and development part aims at highlighting the objectives of the authors (who and why), the underlying principles and theoretical background (how) and the intended audience (to whom).

- The Artefact part addresses technical aspects of the ILE, issues related to the interface (representation and manipulation of mathematical objects), the domain covered by the ILE, the interactivity and tutoring features (types and nature of feedback, student's autonomy, ILE's knowledge of the task), and the role of teacher.

- The Validation part aims at gathering information about empirical validation of the ILE from published papers and available research reports. This aspect seems particularly important in our study to complement our analysis by inspection.

This version of the analysis grid was used to analyse 9 of the ten ILEs concerned by the study. Each ILE was studied by researchers from two different TELMA teams. For some ILEs, two independent grids were filled in, for others, the results of the second study complemented the grid of the first study. The completed grids were then sent to authors of the ILEs to inform them about the study and to get their feedback. Results of an analysis of the completed grids are reported in a compiled and synthetic form in section V. Besides gathering information about the ILEs analysed by using the grid, the teams were invited to report about the methodological tool itself focusing on relevance, appropriateness and clarity of the items, on their applicability to the software analysed, as well as on missing aspects if any.

Taking into account all teams' remarks and suggestions concerning the initial analysis grid, a new, refined version of the analysis grid has been elaborated (see Appendix 2). The most significant change was making an effort to explicit the nature of expected answers. The refined version of the analysis grid was subsequently used to analyse one additional ILE. 


\section{ILEs concerned by the study}

\section{IV.1. Criteria for the choice of the ILEs}

The selection of the ILEs to be studied was based on the following criteria (Nicaud 2006, p. 3):

(a) they were produced by research laboratories or companies;

(b) they were in use in schools on a regular basis or they have been at least experimented by a significant number of students;

(c) they were either products or advanced prototypes;

(d) they have a high level of interactivity.

\section{IV.2. Brief description of the ILEs developed outside TELMA and selected for the study}

IV.2.1. ActiveMath (http://www.activemath.org/)

ActiveMath is a rich web-based learning environment for mathematics (Melis et al. 2001, Melis 2005, Melis et al. 2007). It integrates several tools such as a function Plotting Tool, a Computer Algebra System or an interactive Concept Map Tool, which can be used when necessary. Based on the system's competence assessment, a learner is presented with theoretical and interactive material and has great freedom in the way s/he learns. Interactive exercises respond with feedback and hints to the learner's input. ActiveMath permanently records and assesses the performance of a learner in the exercises and the result can be accessed by the learner. The learner can ask for more information by clicking on mathematical terms or on definitions and by making use of the semantic search facility. ActiveMath provides a variety of contents, e.g. calculus, algebra, combinatorics. 


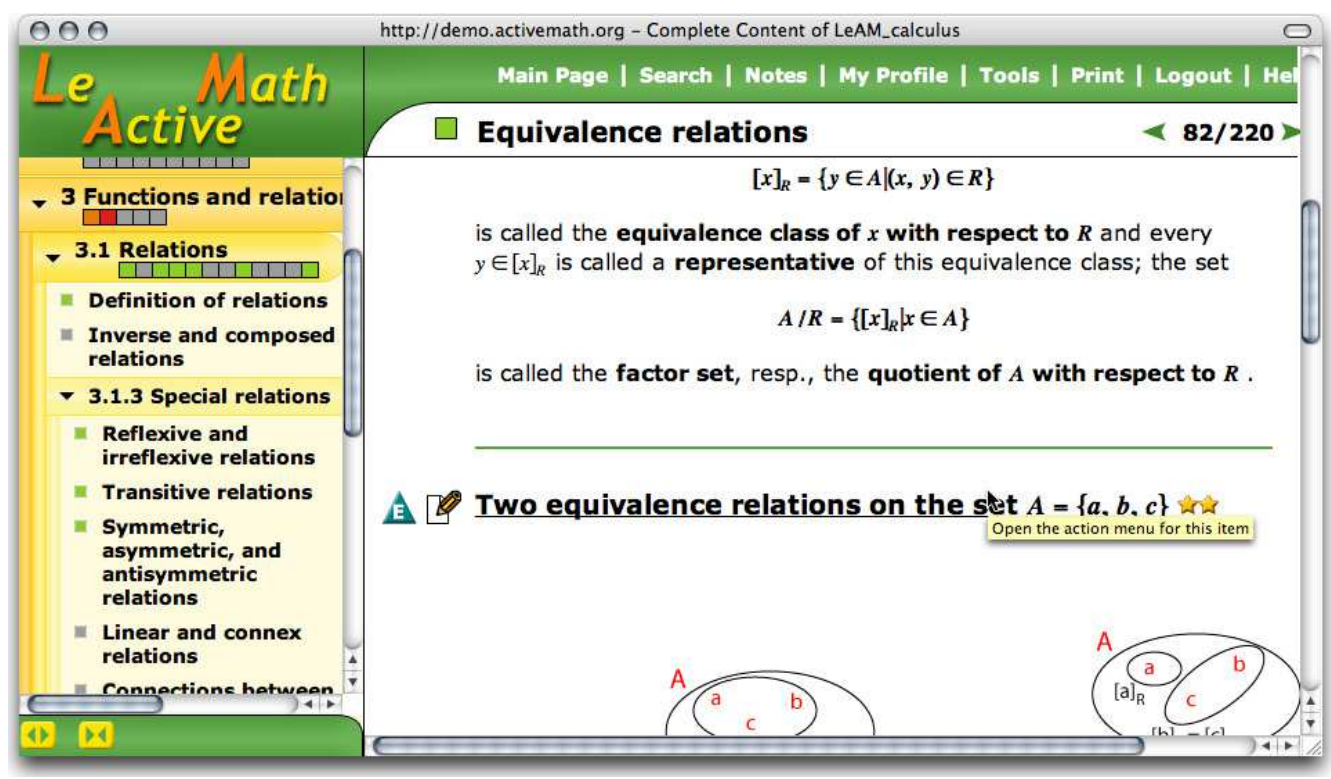

Figure 1. ActiveMath screenshot.

\section{IV.2.2. Anima/Watch (http://k12.usc.edu/AW/)}

AnimalWatch is a web-based tutoring system for middle school mathematics with a specific focus on helping students with the transition from arithmetic to algebra (Arroyo 2000, Arroyo et al. 2003). The system proposes word problems about endangered animal species (e.g., Giant Panda, Right Whale, Mongolian Takhi Wild Horse). For each problem, students can request a multimedia explanation, a worked example requiring the same skills, or a video lesson. They complete the word problems, organized into "virtual narratives". Their progress is customized on the basis of prior math achievement, motivation, and ongoing performance. Current content includes arithmetic, fractions, pre-algebra, and data analysis.

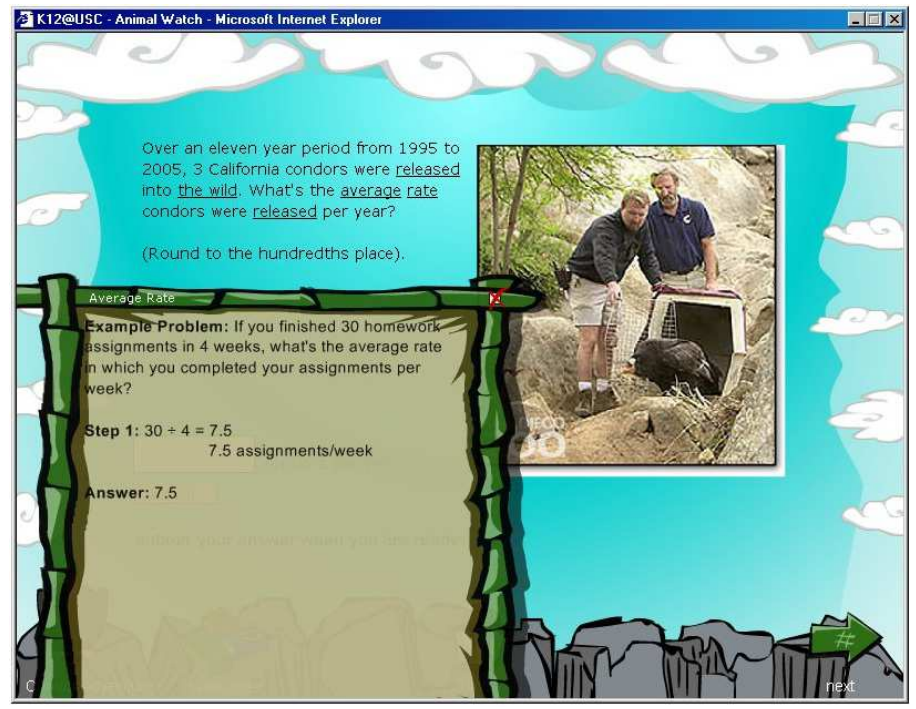

Figure 2. AnimalWatch screenshot. 


\section{IV.2.3. Cognitive Tutor (http://www.carnegielearning.com/)}

The Cognitive Tutor curricula for middle school and high school students include Bridge to Algebra, Algebra I and II, Geometry, Integrated Math and Math Prep products (Koedinger et al. 1997, Aleven and Koedinger 2002). Each curriculum combines software-based, individualized computer lessons with collaborative, real-world problem-solving activities designed to emphasize connections between verbal, numeric, graphic and algebraic representations. Using the software, students receive the benefits of individualized instruction, immediate feedback and coaching. The software includes automated, dynamic assessments that provide personalized instruction for each individual student. Student's progress is constantly monitored, providing immediate feedback for both teachers and students.

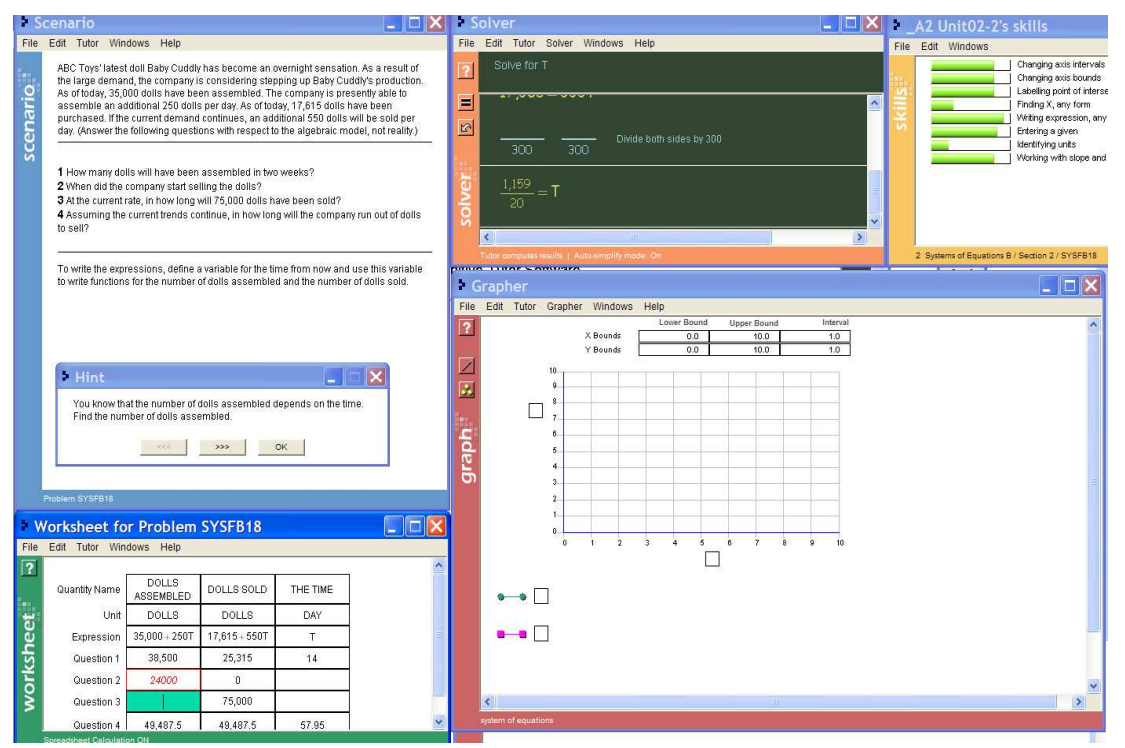

Figure 3. Cognitive Tutor screenshot.

\section{IV.2.4. MATH-TEACHER (http://www.mathkalusa.com/index.html)}

MATH-TEACHER combines an Exploration Environment, which allows for freeform function graphing and investigation, with a tutorial program to master math skills. The tutorial program also allows for free-form input to solve problems. Immediate feedback is provided to each step of the solution, and guidance and help is available on demand. MATH-TEACHER series consists of modules that cover much of the math curriculum of grades 7 through 12, e.g. algebra, calculus, geometry, probability, etc. MATH-TEACHER includes a Test Generator utility which enables the teachers to easily prepare homework and tests. 


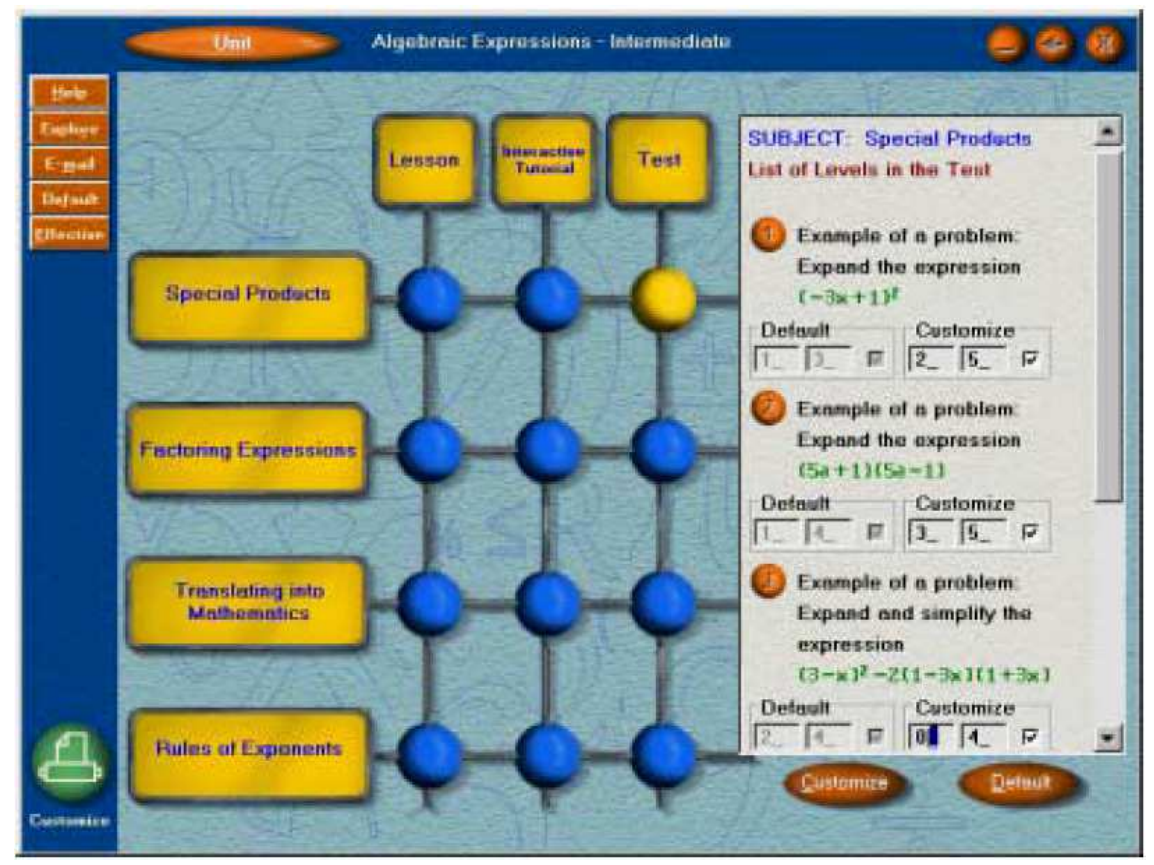

Figure 4. MATH TEACHER screenshot.

\section{IV.2.5. MathXpert (http://www.helpwithmath.com/index.php)}

MathXpert is a computer program designed to help students learn algebra, trigonometry, and one-variable calculus by assisting the student in developing his/her own step-by-step solution (Beeson 1990, 1996). The design of MathXpert follows principles dictated by its intended use to support learning, such as any error has to be avoided because a slight error can throw you completely off track, mathematics is cumulative, therefore you must master each part of the subject before moving on to the next one, or transparency principle meaning that the user chooses the steps and thus controls the development of the computation, while the computer carries out the low-level details.

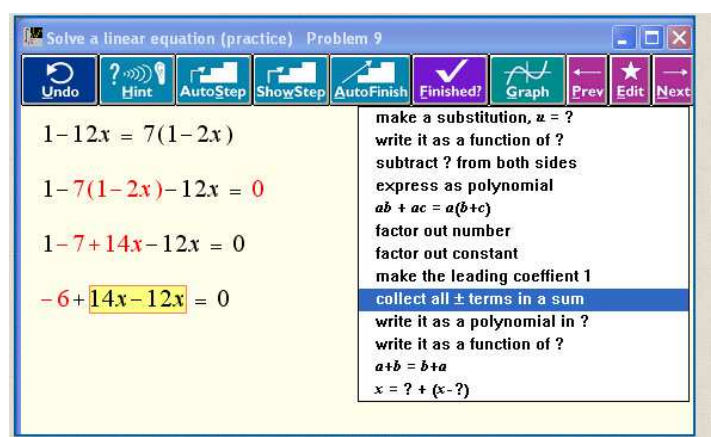

\begin{tabular}{|c|c|c|c|c|c|c|c|c|c|}
\hline \multicolumn{8}{|c|}{ Whelve a linear equation (practice) Problem? } & \multicolumn{2}{|c|}{$-\square x$} \\
\hline Undo & $\begin{array}{c}? \cdot m p))( \\
\text { Hint }\end{array}$ & Autostep & $\begin{array}{ll} \\
\text { ShowStep }\end{array}$ & $T^{-1}$ & Einished? & $\underset{\text { Graph }}{\mathrm{N}}$ & \begin{tabular}{|l|} 
\\
erever \\
\end{tabular} & 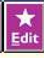 & $\overrightarrow{\underline{N}}$ \\
\hline \multicolumn{4}{|c|}{$1-12 x=7(1-2 x)$} & \multicolumn{4}{|c|}{ the problem } & & \\
\hline \multicolumn{4}{|c|}{$1-7(1-2 x)-12 x=0$} & \multicolumn{4}{|c|}{ subtract $7(1-2 x)$} & & \\
\hline \multicolumn{4}{|c|}{$1-7+14 x-12 x=0$} & \multicolumn{4}{|c|}{$a(b+c)=a b+a c$} & & \\
\hline \multicolumn{4}{|c|}{$-6+14 x-12 x=0$} & \multicolumn{4}{|c|}{ arithmetic } & & \\
\hline \multicolumn{4}{|c|}{$-6+2 x=0$} & \multicolumn{4}{|c|}{ collect like terms } & & \\
\hline
\end{tabular}

Figure 5. MathXpert screenshots.

IV.2.6. Ms. Lindquist (http://www.algebratutor.org/)

Ms. Lindquist is an algebra word problems tutoring software for middle school $\left(6^{\text {th }}-8^{\text {th }}\right.$ grade) and high school $(9$ or 10 th grade) students (Heffernan and 
Koedinger 2000, Heffernan 2003). The software combines a cognitive model of the domain with a pedagogical model of dialog-based tutoring. The algebra model concerns the symbolization, i.e., the task of writing an algebraic expression given a real-world problem context, which is considered as a major determinant of problem difficulty. The tutorial model is based on the observation of an experienced human tutor and captures the rich tutorial strategies specific to the domain of symbolization.

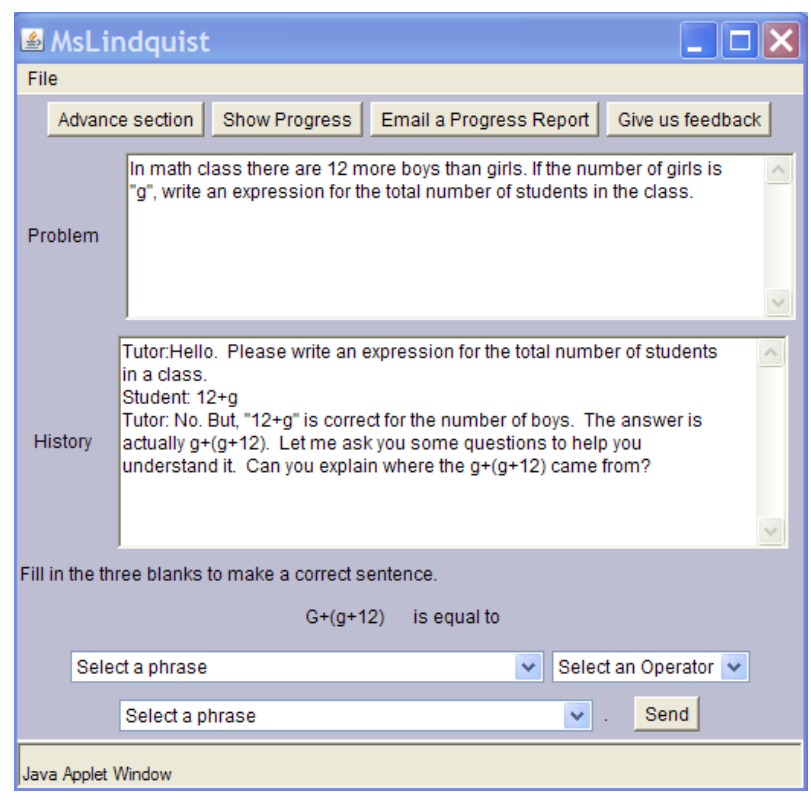

Figure 6. Ms. Lindquist screenshot.

\section{IV.2.7. T-algebra}

T-Algebra is an interactive learning environment for step-by-step solving of algebra problems (Lepp et al. 2005, Prank et al. 2006). The following problems can be worked out by the software: calculation of the values of numerical expressions, operations with fractions, solving linear equations, inequalities and systems of linear equations, and operations with monomials and polynomials. Talgebra makes possible the diagnosis of errors by defining each solution step as consisting of three stages: selection of the transformation rule, marking the parts of the expression the rule will be applied on, entering the result of the operation. 


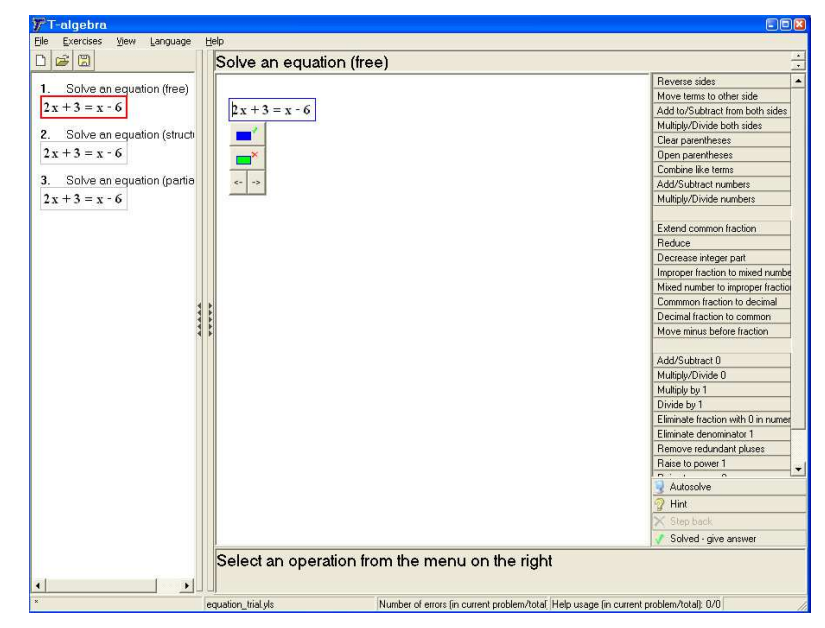

Figure 7. T-algebra screenshot.

\section{IV.3. Brief description of the ILEs developed by TELMA teams}

\section{IV.3.1. Aplusix (http://aplusix.imag.fr/en/)}

Aplusix is an ILE for teaching and learning secondary school arithmetic and algebra (Nicaud et al. 2003, Nicaud et al. 2004). It lets students solve exercises and provides two fundamental feedbacks: it verifies the correctness of the calculations and of the end of exercises. Aplusix has been designed to be integrated into the regular class work: it is close to the paper-pencil environment, it uses a very intuitive editor of algebraic expressions (in two dimensions). It contains 400 patterns of exercises. A number of parameters allow for customisation (e.g., limit or disable commands, prevent the system from giving the solution). Aplusix records all students' actions which can be then observed by the student and the teacher by means of a Replay system. Teachers can also access to statistics concerning their classes indicating amounts of exercises the students have worked on, amounts of well-solved exercises, amounts of incorrect calculations, and scores. 


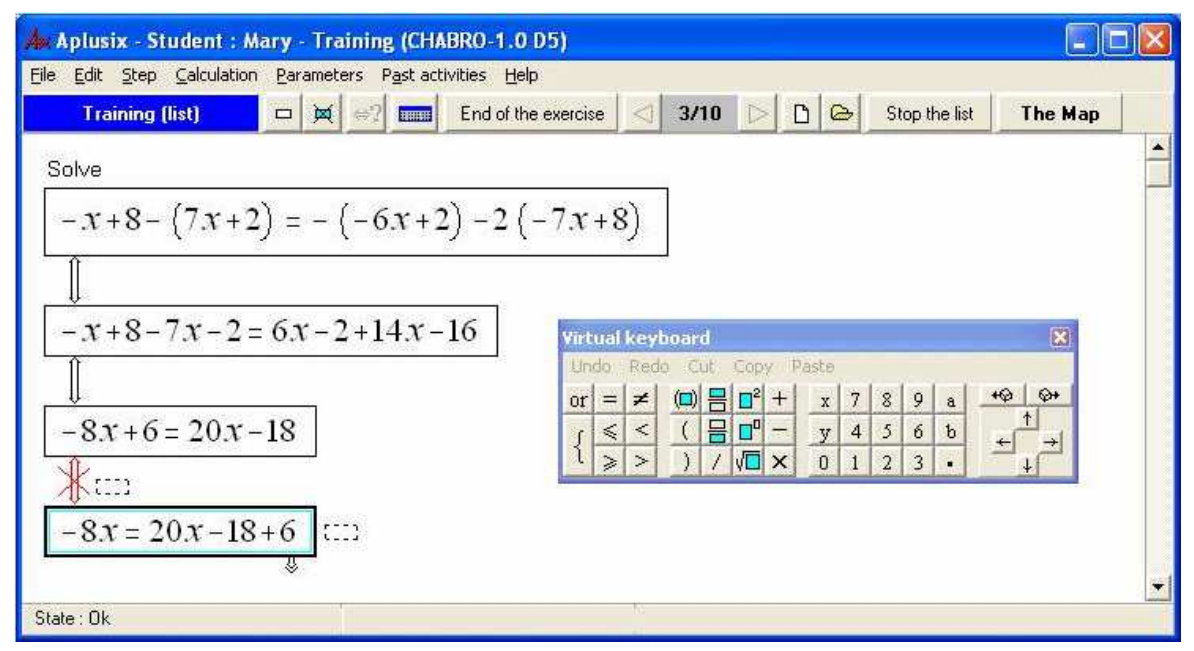

Figure 8. Aplusix screenshot.

\section{IV.3.2. ARILAB-2}

(http://www.cnr.it/istituti/FocusByN_eng.html?cds=102\&nfocus=2)

ARILAB-2 is a multi-environment system focusing on the development of arithmetic problem solving abilities (Cerulli and Mariotti 2000, Bottino and Chiappini 2003). It has been conceived to help teachers design learning environments which take into account the personal characteristics of each student. Using ARILAB-2, the student can build a solution to an arithmetic problem interacting with a structured and interconnected set of different microworlds, such as Abacus microworld, Fraction microworld or Symbolic manipulator microworld. This allows the student to compare different representations of the same mathematical notion, which contributes to a better conceptualisation. The system is structured in a way to support collaborative learning: while solving a problem, the student can interact with peers or with the teacher exchanging messages and solutions.

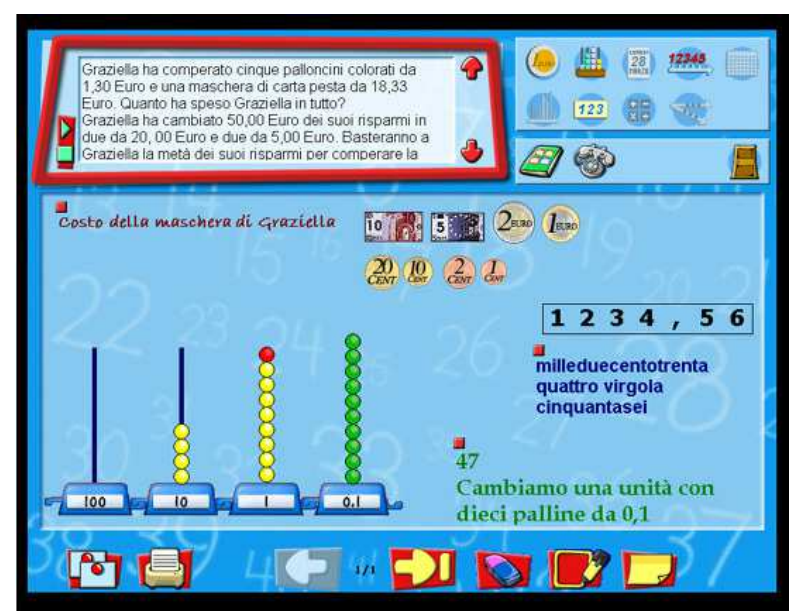

Figure 9. ARILAB-2 screenshot. 


\section{IV.3.3. E-Slate (http://e-slate.cti.gr/)}

E-Slate is an exploratory learning environment that provides a workbench for creating dynamic software with rich functionality by non-programmers (Kynigos 2001, 2007). Educational activity ideas can be turned into software with minimal authoring effort in the form of interactive Microworlds which contain specially designed educational components. A Logo-based scripting language can be used to programme the behaviour of the components and the kind of connections between them. E-Slate components are provided as a kit of pre-fabricated, interoperable computational objects. Software Microworlds can be constructed easily, by plugging components in various configurations.

The "construction kit" is intended to provide developers and authors with tools for producing educational software. However, the educational contingent of the development team has also produced microworlds within E-Slate (e.g., Fraction microworld) that may be used by teachers and students as exploratory learning environments. As well as fully developed microworlds, the team has what it terms "half-baked" technological artefacts, developed specifically for use either by students or by teachers in professional development courses, with the intention that the teachers should change and customise them in order to investigate mathematics themselves or to build microworlds for students to use.

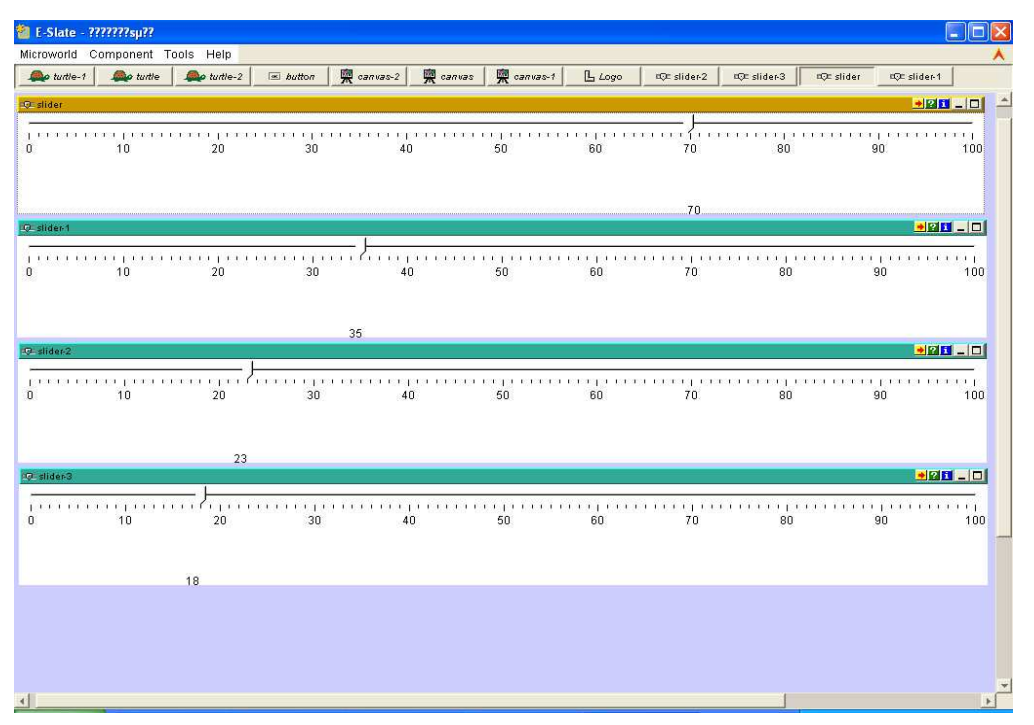

Figure 10. E-Slate Fraction microworld screenshot. 


\section{Results of the ILE study}

The grids filled in collaboratively for each $\operatorname{ILE}^{1}$ were analysed by the authors with the aim of providing a first level comparison of the main aspects of the ILEs. The features and functionalities to be compared were organized into three categories: (1) knowledge domain of the ILE, corresponding roughly to the domain/capacity of the ILE defined by Nicaud (2001), (2) user-ILE interaction covering interaction and tutoring features of the ILE as well as its adaptability (ibid.), and (3) aspects related to the accessibility and availability of the ILE. For each category, several criteria have been chosen to describe the corresponding features of the ILEs as precisely as possible and the results for each criterion and for all 10 ILEs are reported in the tables in Appendices 3-5. Below, we present some of the most salient features of the ILEs and attempt to situate each of the ten ILEs with respect to the others.

\section{V.1. Features related to the knowledge domain}

\section{V.1.1. Algebra content covered by the ILEs}

The analysis of the ILEs from the point of view of mathematical content covered by the ILEs shows that some ILEs are devoted to very specific algebraic domains or tasks, such as fractions (E-slate), symbolization, i.e., translation of word problems into algebraic expressions (Ms Lindquist) or solving linear equations and inequations and systems (T-algebra), while others seem to cover the whole curriculum (Cognitive Tutor, Math Teacher+ or MathXpert). The situation of each of the ten ILEs with respect to the algebraic domain is represented in Fig. 11.

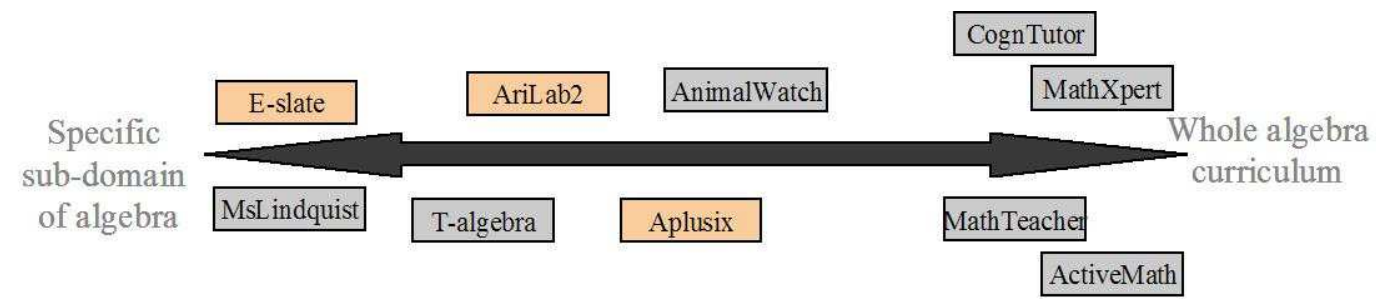

Figure 11. Situation of the studied ILEs with respect to the algebra domain covered.

\footnotetext{
${ }^{1}$ The grids filled in for the ILEs developed by TELMA teams, as well as for T-algebra, can be found in (Trgalova, 2007) and those for the other 6 ILEs developed outside TELMA in (Nicaud, 2006).
} 


\section{V.1.2. Representation systems available in the ILES}

The ILEs differ from the point of view of implemented representation systems allowing to display and manipulate algebraic expressions. For example, T-algebra uses a unique, usual algebraic representation system to handle the expressions, while ActiveMath offers textual, graphical and geometric representation systems in addition to the usual one. Figure 12 represents a ranking of the 10 ILEs with respect to the number of available representation systems.

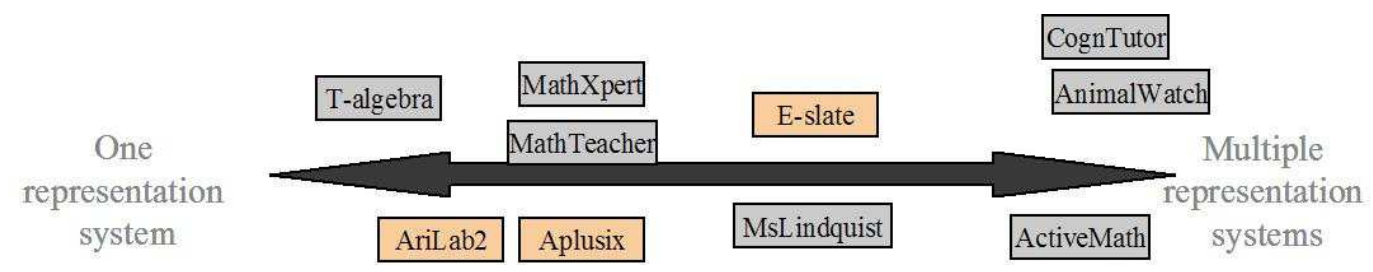

Figure 12. Ranking of the ILEs with respect to the number of different representation systems available for editing and manipulating of algebraic expressions.

\section{V.1.3. Manipulation of algebraic expressions allowed by the ILES}

When analyzing the way algebraic expressions are manipulated in the ILEs, three categories can be identified:

1. input-based systems, such as Aplusix, ActiveMath or MathTeacher+, in which a user enters algebraic expressions and transforms them more or less freely;

2. rule and input-based systems, such as T-algebra or CognitiveTutor, in which the expressions can be entered freely by a user but transformations of expressions are done by choosing a rule from a list of applicable rules. The result of the transformation is provided by the user;

3. rule-based systems, such as AriLab2 or MathXpert, in which expressions are transformed by the system, i.e., a user only selects a transformation rule and a sub-expression on which the transformation should be applied, and the system transforms the expression.

\section{V.2. Features related to the user-ILE interactions}

\section{V.2.1. Feedback provided by the ILES}

The analysis of feedback provided by the different ILEs shows that the designers of the ILEs tackle this issue in very different ways. Some ILEs are designed in a way that each student step is monitored and immediate feedback is fired when an error is detected. The ILEs provide either a visual feedback, for example the error 
is highlighted in red (CognitiveTutor or MathTeacher+), or a hint message is sent to the student (ActiveMath, T-algebra or AnimalWatch). Some ILEs provide feedback about the correct end of an exercise, either immediately (MathTeacher+) or on demand (Aplusix). In some ILEs, specific feedback aimed at scaffolding the student solving processes had been implemented, such as displaying contextsensitive menu and/or activating applicable rules in a list when a (sub) expression is selected (AriLab2 or MathXpert). MsLindquist provides a dialog form immediate feedback depending on chosen tutoring strategy.

\section{V.2.2. Help and/or solution provided by the ILES}

In order to evaluate the degree of autonomy given to a user, hints provided by the ILEs were analyzed. Some of the ILEs provide hint messages as soon as an error is detected (ActiveMath or AnimalWatch), other provide them on demand (CognitiveTutor or MathXpert). The nature of the content of hint messages differs from one ILE to another. For instance, CognitiveTutor provides help messages at three levels, from the most general to the most concrete, leading eventually to the solution of a given task, MathTeacher+ or MathXpert provide step by step guidance toward the solution, and T-algebra suggests an action to use at each step. The ILEs differ also in decisions whether and when to send a correct answer to a given exercise or activity. Thus, for instance, ActiveMath never provides a correct answer, AnimalWatch, CognitiveTutor, MsLindquist or MathTeacher+ send a correct answer after 3 or so mistakes, and finally T-algebra, Aplusix or MathXpert provide a correct answer only on user's demand.

\section{V.3. Features related to technical aspects, accessibility and availability}

\section{V.3.1. Operating systems allowing the ILEs running}

Two of the studied ILEs are web-based systems (ActiveMath and MsLindquist). The others run under Windows, some of them are also supported by Macintosh operating system (AnimalWatch, CognitiveTutor, MsLindquist and MathXpert), and the latter runs also under Linux.

\section{V.3.2. Accessibility of the ILES}

The accessibility of an ILE is guaranteed partly by its license. Half of the studied ILEs are free (AnimalWatch, E-slate, MsLindquist, ActiveMath and T-algebra), 
the other half are commercial products (Aplusix, AriLab2, CognitiveTutor, MathTeacher+ and MathXpert).

\section{Comparison of the ILEs, an attempt to reach a global and visual point of view}

The objective of this part is to reach a global point of view in order to compare the ILEs and to gain a global vision of the different categories of ILEs available, with some general considerations about relative position of each category with respect to the others.

The process, independent from the collaborative work described in section III, was done in two steps by the authors of the present article. In the first step, for each ILE, a radical synthesis of the study of the ILE was done in order to obtain a minimalist representation of the ILE, in the attempt to reach a visual representation of the ILE that represents it as closely to the original as possible. In the second step, the minimalist representations of all the studied ILEs were reduced again and assembled in one object to reach a global landscape of the ILEs universe.

At the same time, the objective of this section is to propose a tool for future analysis of ILEs, in the domain of mathematics, but also other domains. In the math domain, the benefit will be double: first a tool for ILE analysis will be proposed, and second, a representation of the already populated landscape of ILEs for math teaching and learning will be offered, in which a new ILE could be added and described generally.

Most of the work described below relies only on searching and counting some basic key words in the analysis grids presented in section $\mathrm{V}$, but we pay a particular attention to the way the results are presented: we aim at reaching a visual representation of the results rather than provide arrays of figures of the counts, which risks not to be very expressive. We believe that a visual representation could lead to a particular insight about the ILEs of the domain.

\section{VI.1 General considerations and fundamental choices}

The first choice we have made was to determine a small set of directions in which the ILEs will be explored with the aim of reaching our global point of view. The 
reason was that our final result should be visually meaningful and only objects in 2D or 3D have easy-to-interpret representation.

Four directions were first considered: Knowledge, Usage, Control and Availability:

- The Knowledge direction concerns the domain covered by the ILE, in our case mathematics, and more specifically arithmetic and algebra.

- The Usage direction considers functionalities oriented towards teachers and facilities helping them build learning scenarios and organize pedagogical sequences.

- The Control direction is related to features proposed to students in order to support their learning (e.g., feedbacks, interaction features).

- The Availability direction concerns basic material and technological elements that make the ILE available in a particular circumstance. It includes price and license issues, operating system of the computer required for the running of the ILE, the natural language used by the ILE, the domain covered by the ILE. This direction is not cumulative, but Boolean and contextual, i.e., in a given context, the ILE is available or not, and it is quite easy to see, based on the characteristics given by the developers, if the ILE will be available or not in a given context. For this reason, this dimension is not taken into account in the global evaluation.

This choice is slightly different from the one presented in the previous section. The main difference consists in looking at interaction features of the ILEs. While in the first level comparison (see section V), we were interested in features from the point of view of both teachers and students, in this analysis it seems more relevant to extract features that can be considered as oriented more specifically towards the teachers and functionalities that are addressed to students. Obviously, the features for teachers and for students are not exclusive, for this reason, some features and functionalities can be relevant for two or more above mentioned directions. 


\section{VI.2 Achieving a global and visual point of view for each ILE: an ILE as a set of 3 radars}

For each ILE, on the basis of the results summarized in appendices 3-5, we have searched for key words related to each of the three selected directions, and assigned points according to the following sub-directions:

- Knowledge:

- Regarding the sub-direction school level we have assigned 1 point for the ILE that can be used for only 1 to 2 school years, 2 points for the ILE that can be used during 3 to 5 years, 3 points for the ILE that can be used during 6 to 9 years and 4 points for the ILE that can be used 10 years and more. This is one of the main sub-directions of the Knowledge direction.

- Regarding the sub-direction content, we have counted the number of domains covered by the ILE among the following: Arithmetic, Algebra, Word Problem, Analysis, or Others (one point is added for Geometry, Trigonometry, Statistic, since we are interested in the ILEs for arithmetic and algebra). This is one of the main sub-directions of the Knowledge direction.

- As regards the sub-direction representation, we have counted the number of types of representation of mathematical objects available in the ILE among the following: Usual representation, Graphs, Tables, Others (one point is added for Tree, Slider, Line). Note that this sub-direction will also appear in the Control direction. It is one of the main sub-directions of the Knowledge direction.

- Concerning the sub-direction activity, we have counted the number of types of activities or exercises available in the ILE among the following activities: Formal exercises, Word problems, Open problems, Lessons and examples, Proofs and argumentation. This sub-direction will also appear in the Usage direction. This is only a secondary sub-direction of the Knowledge direction.

- Concerning the sub-direction manipulation, we have counted the number of different types of objects from the representation sub-direction that can be edited and manipulated. This sub-direction will also appear in the Usage and the Control directions. This is only a secondary sub-direction of the Knowledge direction. 
- Usage

- Regarding the customisation sub-direction, we have counted the number of ways in which the teacher can customize parts of the ILE, or activities with the ILE: Choose exercises, Create new exercises, Change important parameters of the ILE, Define scenario of use. It is one of the main subdirections of the Usage direction.

- Regarding the use sub-direction, 1 point has been assigned for a declared use in laboratory, 2 points for a declared (experimental) use in a classroom, 3 points for a declared use in a large number of classes and 4 points for a widespread use of the ILE in a big number of classes. It is one of the main sub-directions of the Usage direction.

- The same activity sub-direction as defined in the Knowledge direction. It is one of the main sub-directions of the Usage direction.

- Concerning the flexibility sub-direction, 1 point has been assigned for the ILE with an important guidance of a student's activity (the student is not free to explore the situation, for teachers this means that the situation is reduced to the domain defined by the guidance of the ILE), 2 points have been assigned for a medium guidance and a medium freedom for the student, and as a consequence an average large space for free exploration of a situation, 3 points have been assigned for a great freedom given to the student to explore a situation, which also means that a teacher can imagine a big number of activities around the same situation. One point corresponds to Tutoring systems, three points to Microworld. It is only a secondary sub-direction of the Usage direction. This sub-direction is opposite to the rigidity sub-direction, which could be an interesting concept in another analysis.

- The same manipulation sub-direction as defined in the Knowledge direction. It is only a secondary sub-direction of the Usage direction.

- Control

- Regarding the feedback sub-direction, we have assigned 1 point to an ILE providing feedback on final expression, an additional point to an ILE providing feedback on intermediate expressions and another point to an ILE providing feedback on sub-expressions. It is one of the main subdirections of the Control direction. 
- Regarding the hint sub-direction, we have assigned 1 point to an ILE providing a simple help to students, an additional point to an ILE giving one step toward the solution, another point to an ILE providing guidance up to a solution and still another point if the ILE can solve the given problem. It is one of the main sub-directions of the Control direction.

- Regarding the reaction sub-direction, we have assigned 1 point to an ILE providing a simple alert when an error occurs, an additional point when correction or hint is available when an error occurs and another point when a teacher can choose (by setting a corresponding parameter) to have progress blocked or not when an error occurs. It is one of the main subdirections of the Control direction.

- Regarding the diagnosis sub-direction, we have assigned 1 point to an ILE providing a simple local diagnosis on the steps of the student's activity, 2 points when the diagnosis concerns a whole exercise or a sequence of exercises, an additional point when the diagnosis is global and concern the whole student's activity and another point when this diagnosis is shown and understandable to the teacher of the student. It is one of the main subdirections of the Control direction.

- The same representation sub-direction as defined in the Knowledge direction. It is only a secondary sub-direction of the Control direction.

- The same manipulation sub-direction as defined in the Knowledge direction. It is only a secondary sub-direction of the Control direction.

For example, considering T-Algebra (the only ILE analysed with the revised grid at the end of the process) the table in appendix 3 has been analysed to construct the "Knowledge" radar. Thus for the sub-direction school level, T-Algebra gets 2 points as it is designed for students aged from 12 to 16; for the sub-direction content, it gets 1 point as it is only concerned with algebra; for the sub-direction representation, it gets 2 points as it can deal with algebraic and textual representations. 


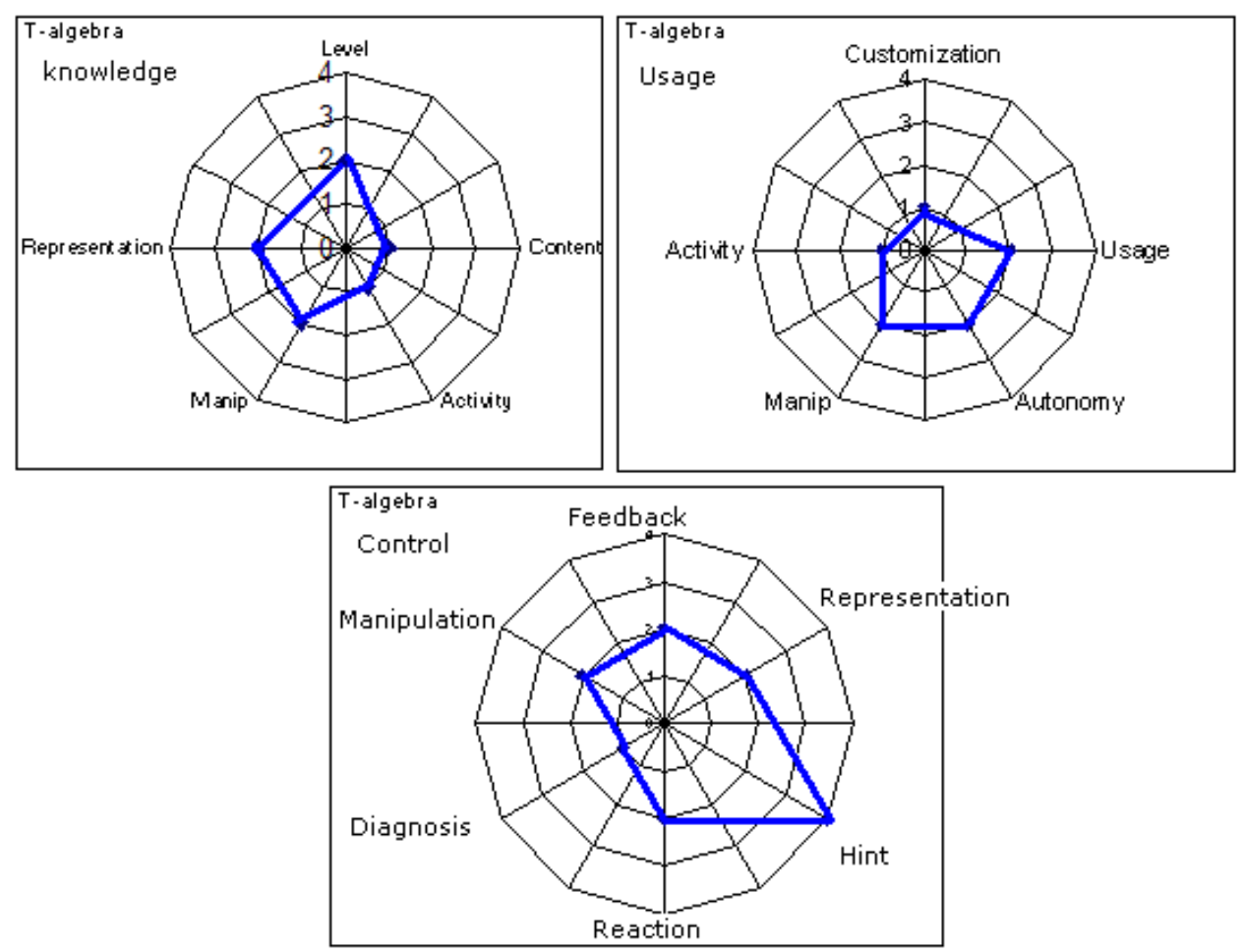

Figure 13. Graphical representation by means of radars of the 3 directions - Knowledge, Usage and Control - of T-algebra.

Two ways of using these radars can be imagined: (1) the three radars relative to a given ILE provide a global view of this ILE, (2) two radars on the same direction relative to two ILEs enable a comparison of these two ILEs as regards the direction at stake.

For example, again considering T-Algebra Fig. 11), the analysis of the three radars reveals the main characteristics of T-Algebra, the directions or domains where T-Algebra is strong, the direction or domains where the software is, comparatively, weak. It shows that T-Algebra is particularly student-friendly (with respect to learning) as it provides a relatively strong control for the students to manage their learning and solving processes and, on the other hand, it offers less possibilities to parameterise the software by teachers (weaker Usage dimension).

Let us consider a second example. A comparison of the "Control" radars of TAlgebra (Fig. 13) and of ActiveMath (Fig. 16) shows differences in terms of control of students' actions to manage their learning. While T-Algebra enhances a hint sub-direction, ActivMath promotes rather an active manipulation subdirection. 

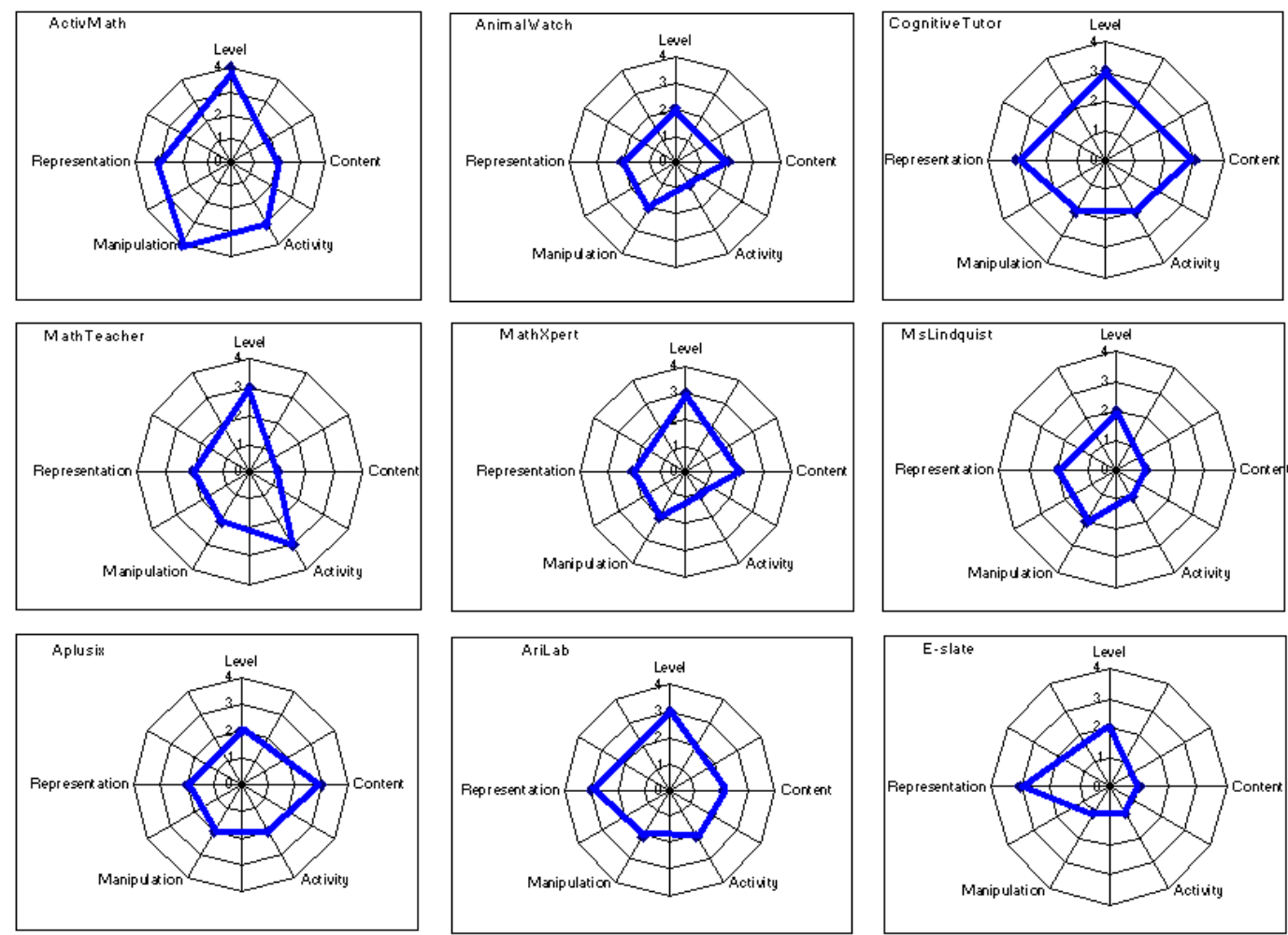

Figure 14. Radars for the Knowledge direction for 9 ILEs.
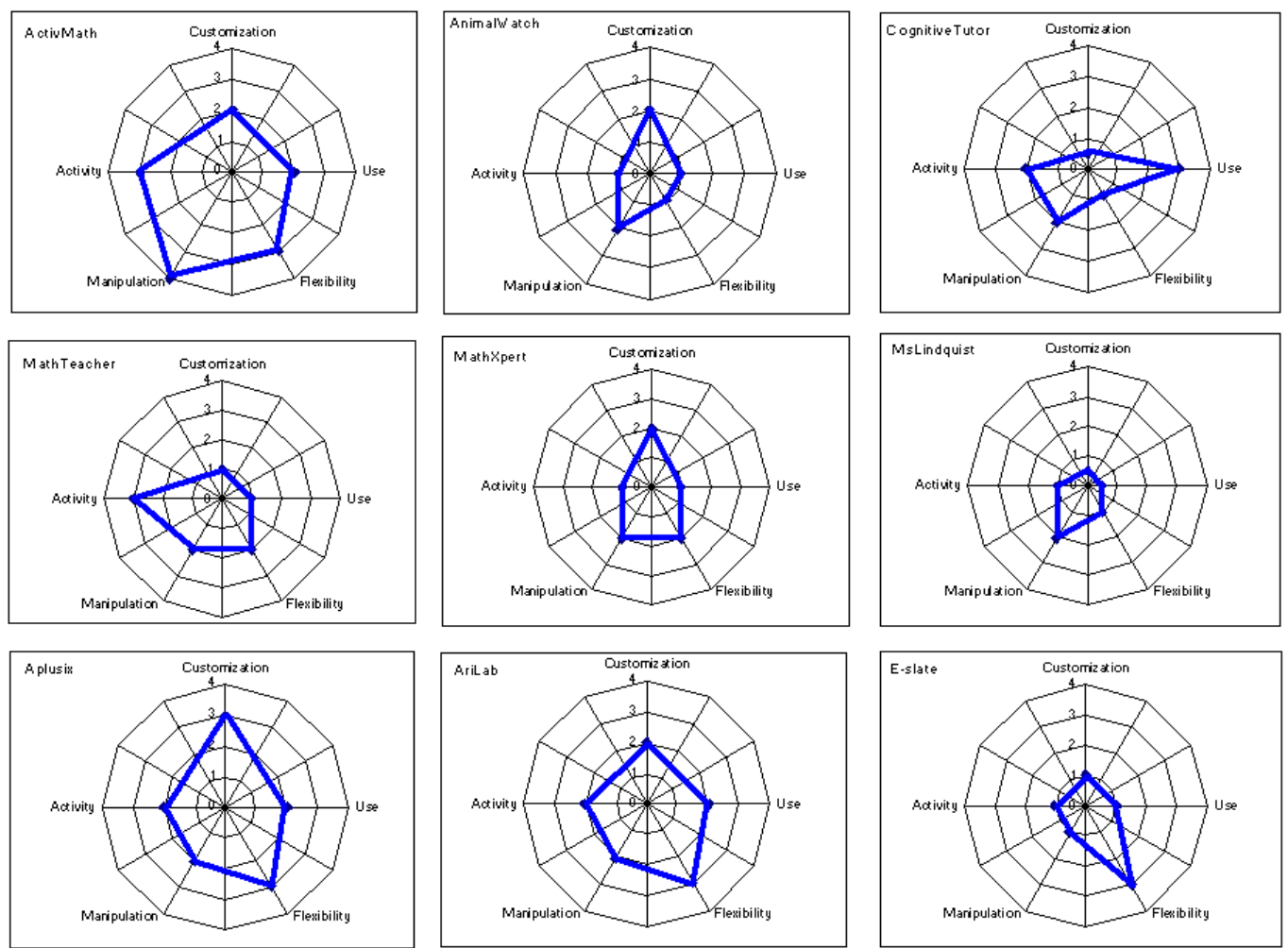

Figure 15. Radars for the Usage direction for 9 ILEs. 

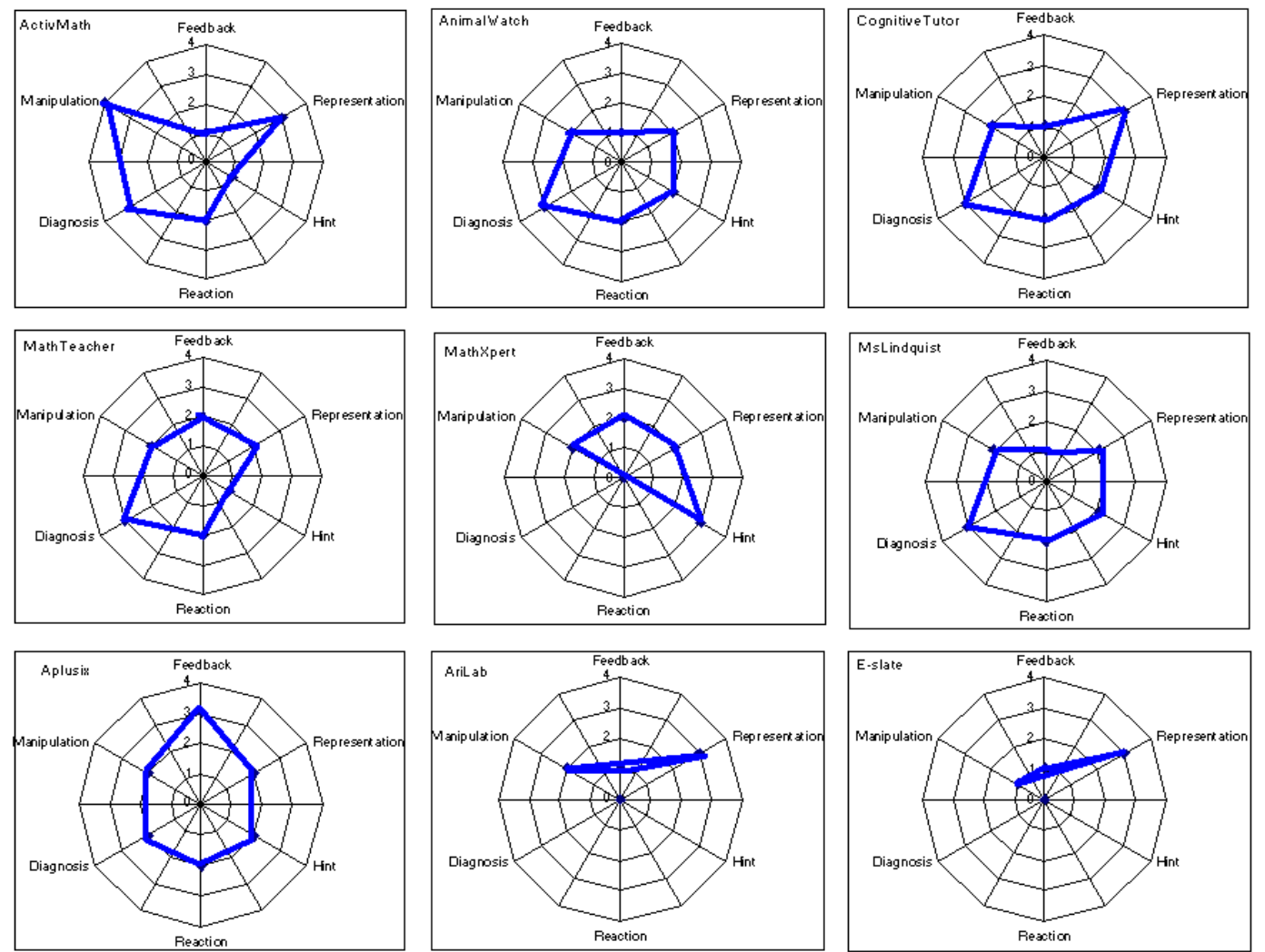

Figure 16. Radars for the Control direction for 9 ILEs.

\section{VI.3. Achieving a global and visual point of view for all ILEs: 3D- space of ILEs}

The work done previously is intended to reduce each ILE into a point with 3 coordinates, one for each direction (as a sum of the sub-directions) and place a 3D point in a space with all the ILEs. In order to take into consideration relative importance of main and secondary sub-directions, for each direction, the sum of all points assigned to a main sub-direction is given the coefficient 1 , and the sum of all points assigned to a secondary sub-direction is given the coefficient $1 / 2$. In this way we obtain the figure 17 (since all the ILEs are very high in the Knowledge direction, and close one to the other, the axis for Knowledge starts with 5 points.) 


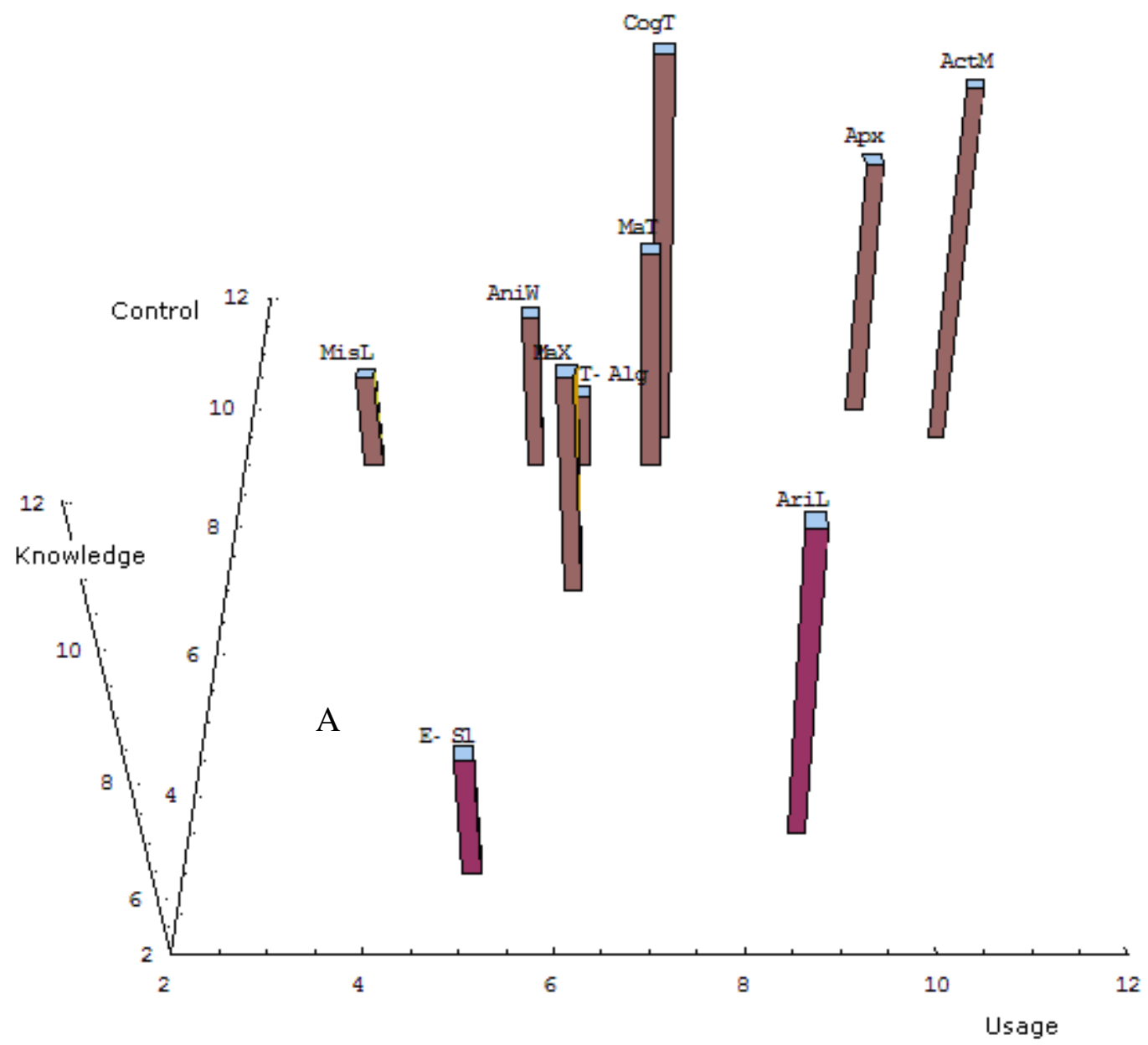

| Figure 17. A 3D map of the ILEs.

If the ILEs that are closest one to the other are grouped together, 5 zones emerge (see Figure 18), which can be described as follows:

- Zone A: ILEs with emphasis on Control only. Such ILEs can be used by students without a lot of help from the teacher, a control is ensured by the ILE. In this zone we will find tutoring systems. With this kind of ILE, the teacher does not have facilities to tune the ILE and forge the activity s/he wants with the ILE. Among the studied ILEs, Mrs Lindquist belongs to this zone.

- Zone B: ILEs with tradeoffs between Control and Usage, but the control dimension is stronger. It is the most populated zone by the studied ILEs, it contains AnimalWatch, Cognitive Tutor, Math Teacher and MathXpert. The ILEs from this zone can be used autonomously by students, the teacher's role may be limited to the choice of activities for the students. This zone seems to be the one where mathematics teachers are the most active in the design of ILEs. 
- Zone C: ILEs with equal emphasis on Control and Usage. Aplusix and ActiveMath belong to this zone. With such ILEs, the teacher needs to prepare, at least partially, the students' activities. This zone seems to be the one where computer scientists are the most active in the design of the ILEs.

- Zone D (empty zone): ILEs with tradeoffs between Control and Usage, however the usage dimension is stronger. No ILE among those studied belongs to this zone.

- Zone E: ILEs with emphasis on Usage only. It corresponds to a microworld, or an authorware ILE. Generally, such ILE does not provide any activity; therefore the teacher is in charge of designing learning activities. AriLab2 and E-Slate are within this zone.

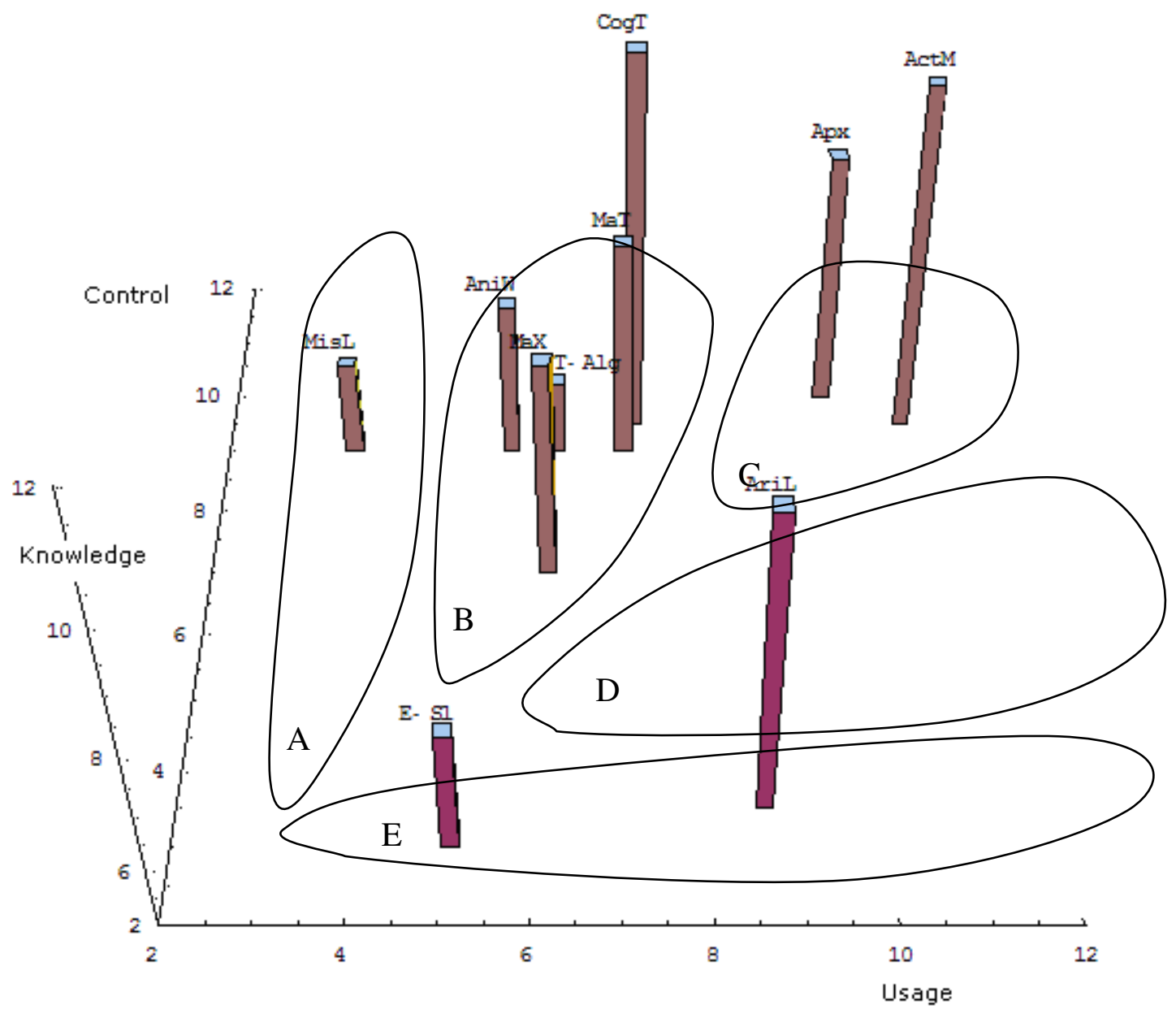

Figure 18. Five zones in the 3D map of the ILEs landscape. 


\section{Discussion and conclusion}

This paper presents TELMA approach to a study of interactive learning environments for mathematics, especially arithmetic and algebra. This study aimed at gaining a deeper insight in the features and functionalities of these systems, as well as at getting a more comprehensive view of research projects concerned by the development of such systems. Specific methodological tool in form of a grid has been elaborated by TELMA to frame the analysis by inspection of a number of aspects of the systems. It has been consequently applied to the analysis of ten existing state-of-the-art ILEs.

Although evaluation of ILEs is not a new issue and there exist numerous research works proposing methods and tools for ILE analysis and classification, it seems that they are used rather at an individual level, for evaluating a single given ILE. These methods and tools are rarely applied, by their authors or other researchers, in order to perform comparative analyses of computer-based educational software. This situation is rather understandable: a strict separation between the definition of an evaluation and the design of an ILE has a positive aspect since it ensures a better objectivity in evaluating the ILE. On the other hand, as these methods are used rather by individuals, they are often personalized and focusing on specific features of the designed ILE. As a consequence, these evaluations can rarely be compared and a global image of the domain of ILEs can hardly be achieved.

For this reason, we believe that TELMA study reported in this paper brings a valuable contribution to the domain of ILEs for arithmetic and algebra from at least two points of view: (1) it leads to a characterization of several ILEs by means of radars, which allows comparing the ILEs with respect to some selected features, and (2) it allows a classification of the ILEs into zones determined by available features in the ILEs. Such results may be of a high interest not only from the research point of view, but also for potential users of these ILEs, teachers and students, who often complain about the difficulty to choose an appropriate computer-based program, which matches the best their own purposes.

It is worthwhile to emphasize TELMA methodological approach to the analysis of ILEs: first, each ILE developed outside TELMA has been studied by two independent teams, involving both computer scientists and researchers in mathematics education, to ensure an objective and undistorted result. Second, the ILEs developed by TELMA teams have been studied by teams who have not been 
involved in the design and the development of the ILE and who have used it in a teaching experiment conducted within the project. This decision was motivated by one of the results from the work done within TELMA, which is the impact of theoretical backgrounds, representation and context issues on the design, development and use of the ILE. For more details about these results, see respectively (Artigue \& al., Morgan \& al., Kynigos \& Psycharis, all in this issue). As was already mentioned, the ILE study was done not to evaluate one system against the others and thus establish a list of systems of better quality, but rather to gain a deeper insight in state-of-the-art technological tools devoted to the teaching and learning arithmetic and algebra. It attempted to explore transversally different directions in such tools. The results provide a better global image of the domain and allow positioning better the ILEs we develop ourselves within this landscape. But obviously, we need to be aware of limits of this study residing mainly in the fact that the global image we give about the ILE domain is necessarily subjective. The directions we focus on (knowledge, usage, and control) correspond to our personal choices, motivated by our personal perceptions of features and functionalities of an ILE for arithmetic and algebra. Numerous elements have not been studied or taken into account, such as availability, economic elements, basic user-interface importance, internationalization and national context etc. It is clear that considering other directions and features would lead to a different comparison and to a different global image of the ILE landscape. Nevertheless, we hope that the work initiated by TELMA contributes to a better understanding of the ILEs domain and opens ways to further research in this direction.

\section{Acknowledgements}

The study reported in this paper was conducted within the TELMA project, contract $\mathrm{N}^{\circ}$ IST 507838, supported by the Network of Excellence Kaleidoscope. 


\section{References}

Aleven, V., Koedinger, K. (2002). An effective metacognitive strategy: learning by doing and explaining with a computer-based Cognitive Tutor. Cognitive Science, 26(2), 147-179.

Arroyo, I. (2000). Animalwatch: an arithmetic ITS for elementary and middle school students, "Learning Algebra with the Computer" Workshop, Fifth International Conference on Intelligent Tutoring Systems, Montreal, Canada, June 2000.

Arroyo, I., Beck, J.E., Beal, C.R. and Woolf, B.P. (2003). Learning within the ZPD with the AnimalWatch intelligent tutoring system, American Education Research Association Annual Meeting Symposia, Chicago, IL.

Artigue, M., Cerulli, M., Haspekian, M. and Maracci, M. Connecting and integrating theoretical frames: the TELMA contribution, International Journal of Computers for Mathematical Learning, (this issue).

Beeson, M. (1990). Mathxpert, a computerized learning environment for Algebra, Trigonometry and Calculus, Journal of Artificial Intelligence in Education, 65-76.

Beeson M. (1996). Design Principles of Mathpert: Software to support education in algebra and calculus. In Kajler, N. (ed.), Human Interfaces to Symbolic Computation, Springer-Verlag. Bottino, R.M. and Chiappini, G. (2003). An innovative teaching and learning environment for school mathematics, Proceedings of the International Conference T.E.L.'03: Technology

Enhanced Learning '03, ACM Italian Chapter And ASI, 73-80.

Bottino, R.M. and Kynigos, C. Mathematics Education \& digital technologies:facing the challenge of networking European research teams, International Journal of Computers for Mathematics Learning, (this issue).

Cerulli, M. and Mariotti, M.A. (2000). A symbolic manipulator to introduce pupils to algebra theory. Proceedings of Workshop W6 "Learning Algebra with the Computer, a Transdisciplinary Workshop”, ITS'2000, Montreal.

Cerulli, M., Pedemonte, B. and Robotti, E. (2005). An integrated perspective to approach technology in mathematics education, In Bosch, M. (Ed.) (2006), Proceedings of CERME 4. IQS Fundemi Business Institute, Sant Feliu de Guixols, Spain, 1389-1399 (http://telearn.noekaleidoscope.org/warehouse/Cerulli-M-Pedemonte-P-Robotti-E-2006.pdf).

Chaachoua, H., Nicaud, J., Bronner, A. and Bouhineau, D. (2004). APLUSIX, A learning environment for algebra, actual use and benefits. In Proceedings of ICME-10.

Heffernan, N. and Kenneth R. Koedinger, K. (2000). Building a 3rd Generation ITS for Symbolization: Adding a Tutorial Model with Multiple Tutorial Strategies, Workshop entitled "Learning Algebra with the computer, a transdisciplinary workshop". Intelligent Tutoring Systems 2000 Conference, 12-22.

Heffernan, N. (2003). Web-based evaluations showing both cognitive and motivational benefits of the Ms. Lindquist tutor. In F. Verdejo and U. Hoppe (Eds), 11th International Conference Artificial Intelligence in Education, Sydney, Australia. IOS Press, 115-122.

Hû, O., Trigano, Ph. (2000). A tool for evaluation using dynamic navigation in a set of questions. In Proceeding of TFWWG'2000 Workshop, International Special Interest Group (SIG) on Tools for Working with Guidelines, Biarritz, France. 
Koedinger, K., Anderson, J. R., Hadley, W. H. and Mark, M. A. (1997). Intelligent tutoring goes to school in the big city, International Journal of Artificial Intelligence in Education 8, 30-43. Kynigos, C. (2001). E-slate Logo as a basis for constructing microworlds with mathematics teachers. Proceedings of the Ninth Eurologo Conference, Lintz, Austria, 65-74.

Kynigos, C. (2007). Using half-baked microworlds to challenge teacher educators' knowing. International Journal of Computers for Mathematical Learning 12(2), 87-111.

Kynigos, C. and Psycharis, G. The role of context in research involving the design and use of digital media for the learning of mathematics: boundary objects s vehicles for integration, International Journal of Computers for Mathematical Learning, (this issue).

Lepp, D., Issakova, M. and Vaiksaar, V. (2005). Expression Editor Features That Simplify Student Work On Manipulating Expressions. Proceedings of the 7th International Conference on Technology in Mathematics Teaching, Bristol, UK, 26-29 July 2005. Volume 1, 259-266. Melis, E., Andres, E., Franke, A., Frischauf, A., Goguadse, G., Libbrecht, P., Pollet, M. and Ullrich, C. (2001). ActiveMath: A web-based learning environment, International Journal of Artificial Intelligence in Education 12, 385-407.

Melis, E. (2005). Design of Erroneous Examples for ActiveMath Proceedings of the 12th International Conference on Artificial Intelligence in Education (AIED 2005).

Melis, E., Moormann, M., Ullrich, C., Goguadze and G., Libbrecht, P., (2007). How ActiveMath Supports Moderate Constructivist Mathematics Teaching. In Proceedings of the 8th International Conference on Technology in Mathematics Teaching, Hradec Kralove, Czech Republic.

Morgan, C., Mariotti, M. A., and Maffei, L. Representation in computational environments: epistemological and social distance, International Journal of Computers for Mathematics Learning (this issue).

Nanard, J., Nanard, M., (1998). La conception d'hypermédias. Hypertextes et Hypermédias, numéro hors série, 15-34.

Nicaud, J.-F. (2001). A questionnaire for educational environments for algebraic reasoning. Unpublished paper presented in a working group in the Melbourne ICMI study in 2001. Nicaud, J.-F., Bouhineau, D., Chaachoua, H., Huguet, T. and Bronner A. (2003). A computer program for the learning of algebra: description and first experiment. In Proceedings of the PEG 2003 conference, St. Petersburg, Russia, June 2003.

Nicaud, J.-F., Bouhineau, D. and Chaachoua, H. (2004). Mixing Microworld and CAS Features in Building Computer Systems that Help Students Learn Algebra. International Journal of Computers for Mathematical Learning 9(2), 169-211.

Nicaud, J.-F. (Ed.) (2006). State of the art of didactical ICT systems. Deliverable D20.05.01. TELMA Project, Kaleidoscope network of excellence.

Nogry, S., Jean-Daubias, S. and Ollagnier-Beldame, N. (2004), Evaluation des EIAH : une nécessaire diversité des méthodes. In TICE 2004, Compiègne, France, 265-271 (Retrieved from http://liris.cnrs.fr/publis/?id=1299, July $\left.1^{\text {st }} 2008\right)$.

Prank, R., Issakova, M., Lepp, D., Vaiksaar, V. and Tõnisson, E.. (2006). Problem solving environment T-algebra. Proceedings of 7th International Conference Teaching Mathematics: Retrospective and Perspectives, Tartu, Estonia, May 12-13, 190-197. 
Senach B. (1993). L'évaluation ergonomique des interfaces homme - machine. In J.-C. Sperandio (Ed.), L'ergonomie dans la conception des projets informatiques, Octares éditions, 69-122. Senach B. (1990). Evaluation ergonomique des interfaces homme-machine : une revue de la littérature. Rapport de recherche, INRIA.

Squires, D., Preece, J. (1999). Predicting quality in educational software: Evaluating for learning, usability, and the synergy between them. Interacting with Computer 11(5), 467-483.

Tchounikine, P., Baker, M., Balacheff, N., Baron, M., Derycke, A., Guin, D., Nicaud, J.-F. and Rabardel, P. (2004). Platon-1: quelques dimensions pour l'analyse des travaux de recherche en conception d'EIAH. Rapport de l'Action Spécifique «Fondements théoriques et méthodologiques de la conception des EIAH », département STIC du CNRS (http://hal.archivesouvertes.fr/docs/00/19/01/79/PDF/Tchounikine_2004.pdf).

Trgalova, J. (Ed.) (2007). Analysis of a selection of interactive learning environments for mathematics, Deliverable D20.05.02, TELMA project, Kaleidoscope network of excellence.

Tricot, A., Plégat-Soutjis, F., Camps, J.-F., Amiel, A., Lutz, G., and Morcillo, A. (2003). Utilité, utilisabilité, acceptabilité: interpréter les relations entre trois dimensions de l'évaluation des EIAH. In Actes de la Conférence Environnements Informatiques pour l'Apprentissage Humain, Strasbourg, 391-402.

Trigano, P., Giacomini-Pacurar, E. (2004). CEPIAH, a method for Evaluation and Design of Pedagogical Hypermedia, Higher Education in Europe 29, n, $116-136$ (Retrieved from http://archiveseiah.univ-lemans.fr/article.php@identifier=oaiX511hal.archivesouvertes.frX511hal-00004236_v1, July $\left.1^{\text {st }} 2008\right)$.

Vivet, M. (1996). Evaluating Educational Technologies : Evaluation of Teaching Material Versus Evaluation of Learning? In Proceedings of the Third International Conference, CALISCE '96, San Sebastian, Spain, July 29-31, 1996, 37-38.

Wenger, E. (1987). Artificial intelligence and tutoring systems: computational and cognitive approaches to the communication of knowledge. Los Altos, Calif.: Morgan Kaufmann Publishers. 


\section{Appendix 1: Initial grid designed by TELMA teams to analyse ILEs for arithmetic and algebra}

\section{Design and development}

\section{Name of the ILE:}

Date of the study:

Who
People/organisation involved in the design
Interaction between these participants

\begin{tabular}{|c|c|}
\hline $\begin{array}{l}\text { For whom } \\
\text { Intended Audience }\end{array}$ & \\
\hline $\begin{array}{l}\text { Distribution } \\
\text { License, price }\end{array}$ & \\
\hline \multicolumn{2}{|c|}{ Artefact } \\
\hline $\begin{array}{l}\text { Technical aspects } \\
\text { Operating System (or Web) } \\
\text { Programming Language } \\
\text { Translations }\end{array}$ & $\begin{array}{l}\text { Interactivity } \\
\text { Microworld or hypermedia }\end{array}$ \\
\hline $\begin{array}{l}\text { Interface } \\
\text { Representations: } \\
\quad{ }^{*} \text { what rep. } \\
{ }^{*} \text { nature (usual, new) } \\
\text { * quality (poor, medium, rich) } \\
\text { Manipulations: } \\
\text { * on what (objects, rules...) } \\
\quad \text { * quality (pleasant, painful) }\end{array}$ & $\begin{array}{l}\text { Answer } \\
\text { Multiple choice question } \\
\text { Final open answer } \\
\text { Step by step answer } \\
\text { No answer }\end{array}$ \\
\hline $\begin{array}{l}\text { Domain } \\
\text { Mathematical content: } \\
\text { Sort of exercises } \\
{ }^{*} \text { formal exercises } \\
\text { * word problems }\end{array}$ & $\begin{array}{l}\text { Autonomy } \\
\text { Degree of student's autonomy } \\
\text { Self-evaluation }\end{array}$ \\
\hline $\begin{array}{l}\text { Types of activities } \\
\text { Lecture } \\
\text { Examples solved by the ILE } \\
\text { Exercises to be solved by the student }\end{array}$ & $\begin{array}{l}\text { Knowledge of the task } \\
\text { The ILE knows what is the student's task } \\
\text { The ILE can provide hint } \\
\text { The ILE can provide the solution } \\
\text { The ILE can solve the exercise step by step }\end{array}$ \\
\hline $\begin{array}{l}\text { Feedback } \\
\text { Immediate/delayed } \\
\text { Nature } \\
\text { Diagnosis }\end{array}$ & $\begin{array}{l}\text { Teacher's role } \\
\text { Parameterization } \\
\text { Production of scenarios } \\
\text { Production of exercises }\end{array}$ \\
\hline \multicolumn{2}{|c|}{ Validation, usage, experimentation } \\
\hline $\begin{array}{l}\text { Experimentation } \\
\text { Usage analysis } \\
\text { Qualitative results } \\
\text { Quantitative results }\end{array}$ & $\begin{array}{l}\text { Usage } \\
\text { Familiarization with the ILE } \\
\text { Evolution }\end{array}$ \\
\hline
\end{tabular}




\section{Name of the ILE: \\ Date of the study:}

\section{Design and development}

This part is to be filled out based on available documents (articles, reports...).

Who:

Authors of the ILE

1. People/organisation involved in the design:

Field of people involved in the design (computer science, psychology, educators...)

2. Interaction between these participants:

What each category of designers is in charge of?

Why:

Motivation, educational goals of the designers

1. Aims of the design:

\section{Research questions:}

\section{For whom:}

Intended audience, school level...

How:

Main choices and decisions made in the design phase, and a rationale

1. Constraints affecting the design

2. Underlying theories and principles

\section{Distribution:}

1. Licence

2. Price

\section{Artefact}

This part is to be filled out based on the inspection of the system.

\section{Technical aspects:}

1. Operating System (or Web):

What operating systems or Web browsers the ILE functions with?

\section{Translations:}

In what languages the ILE is available?

Mathematical content:

Parts of arithmetic and algebra curriculum covered by the ILE

\section{Interface:}

How mathematical objects are represented within the ILE, and how these can be manipulated?

1. Representations of mathematical objects available in the ILE:

1.1. Description

1.2. Distance between institutional and/or cultural representations and the representations available in the ILE

\section{Manipulation:}

What can be manipulated (objects, rules...) and how? 
Types of activities:

For what purposes can the ILE be used (what modalities of employment are envisaged by the designers)?

1. Does the ILE provide lectures (definitions, theorems, proofs...)?

2. Does it provide solved examples?

3. Does it provide exercises to be solved by the student? If so:

3.1. What kinds of exercises (formal exercises, word problems, multiple choice questions...)?

3.2. What kind of answer is expected (step by step answer, final answer...)

3.3. Is it possible to give no answer?

Interactivity:

Features of the ILE concerning user-ILE interactions

1. Feedback

1.1. What kind of feedback is provided by the ILE?

1.2. When a feedback is provided?

\section{Knowledge of the task}

2.1. Does the ILE know what the student's task is?

2.2. Can the ILE provide hints?

2.3. Can the ILE provide the solution of the given task?

2.4. Can the ILE solve a given task step by step?

Autonomy:

Features of the ILE allowing an autonomous work with the ILE

1. What is the degree of student's autonomy?

2. Does the ILE allow self-evaluating?

3. Does the ILE provide a diagnosis of the student's knowledge or skills?

Teacher's role:

Features of the ILE concerning allowing customisation of the ILE by a teacher

1. Are there any parameters a teacher can set up in order to adapt the ILE to her/his own objectives?

2. Does the ILE allow creating exercises? Learning scenarios?

\section{Experimentations}

This part is to be filled out based on available documents (articles, reports...).

\section{Experimentation}

Empirical evaluation of the ILE (instrumental issues, evidence of an impact on learning)

\section{Usage analysis}

1.1. Is the interface user-friendly allowing a quick familiarization with the ILE?

1.2. Is the ILE used at a regular base?

2. Is there evidence of an impact on students' learning?

2.1. From a quantitative point of view (improvement of students' achievements...)?

2.2. From a qualitative point of view (overcoming common misconceptions....)? 


\section{Appendix 3: Knowledge domain of the 10 ILEs}

\begin{tabular}{|c|c|c|c|c|c|}
\hline & $\begin{array}{l}\text { School } \\
\text { level }\end{array}$ & $\begin{array}{l}\text { Mathematical } \\
\text { content }\end{array}$ & Representation & Manipulation & Types of activities \\
\hline $\begin{array}{l}\text { Active } \\
\text { Math }\end{array}$ & $16 \&$ up & $\begin{array}{l}\text { Equations, } \\
\text { fractions, } \\
\text { functions } \\
\text { Algebra: } \\
\text { introduction to } \\
\text { groups }\end{array}$ & $\begin{array}{l}\text { Textual } \\
\text { Graphical } \\
\text { Geometric } \\
\text { Algebraic (usual) }\end{array}$ & $\begin{array}{l}\text { On graphs, texts, } \\
\text { numbers, geometric } \\
\text { figures, applets, } \\
\text { expressions }\end{array}$ & $\begin{array}{l}\text { Lessons } \\
\text { Solved examples } \\
\text { Proofs of theorems } \\
\text { Open and multiple } \\
\text { choice questions } \\
\text { Formal exercises }\end{array}$ \\
\hline $\begin{array}{l}\text { Animal } \\
\text { Watch }\end{array}$ & $9-12$ & $\begin{array}{l}\text { Basic arithmetic } \\
\text { Fractions } \\
\text { Word pbs }\end{array}$ & $\begin{array}{l}\text { Textual } \\
\text { Graph/diagrams } \\
\text { Algebraic (usual) } \\
\text { Numerical } \\
\end{array}$ & $\begin{array}{l}\text { On numbers and } \\
\text { diagrams }\end{array}$ & Word problems \\
\hline $\begin{array}{l}\text { Cog. } \\
\text { Tutor }\end{array}$ & $\begin{array}{l}10-18 \\
\text { college }\end{array}$ & $\begin{array}{l}\text { Bridge to } \\
\text { algebra } \\
\text { Algebra I, II } \\
\text { Algebra II }\end{array}$ & $\begin{array}{l}\text { Textual } \\
\text { Numerical } \\
\text { (table) } \\
\text { Graphical } \\
\text { Algebraic (usual) }\end{array}$ & $\begin{array}{l}\text { Entering numbers, } \\
\text { unit labels and } \\
\text { expressions } \\
\text { Choosing a } \\
\text { transformation, } \\
\text { entering arguments }\end{array}$ & $\begin{array}{l}\text { Formal, computational } \\
\text { exercises } \\
\text { Word problems }\end{array}$ \\
\hline $\begin{array}{l}\text { Math } \\
\text { Teacher+ }\end{array}$ & $11-18$ & Algebra 1, 2 & $\begin{array}{l}\text { Algebraic (usual) } \\
\text { Graphical }\end{array}$ & $\begin{array}{l}\text { On algebraic rules } \\
\text { and expressions } \\
\text { Experimenting with } \\
\text { graphs }\end{array}$ & $\begin{array}{l}\text { Lessons } \\
\text { Solved examples } \\
\text { Formal exercises } \\
\text { Word problems }\end{array}$ \\
\hline $\begin{array}{l}\text { Math } \\
\text { Xpert }\end{array}$ & $\begin{array}{l}10-18 \\
\text { univ. }\end{array}$ & Algebra & $\begin{array}{l}\text { Algebraic (usual) } \\
\text { Graphical }\end{array}$ & $\begin{array}{l}\text { On alg. expressions, } \\
\text { (in)equations, } \\
\text { graphs }\end{array}$ & $\begin{array}{l}\text { Formal exercises (ex. } \\
\text { eliminate rational } \\
\text { exponents...) }\end{array}$ \\
\hline $\begin{array}{l}\text { Mrs } \\
\text { Lindquist }\end{array}$ & $12-16$ & Symbolization & $\begin{array}{l}\text { Textual } \\
\text { Numerical } \\
\text { Algebraic (usual) }\end{array}$ & $\begin{array}{l}\text { Inserting verbal } \\
\text { sentences via pull } \\
\text { down menus } \\
\text { Inserting alg. expr. }\end{array}$ & Word problems \\
\hline $\begin{array}{l}\text { T- } \\
\text { algebra }\end{array}$ & $12-16$ & $\begin{array}{l}\text { Solving linear } \\
\text { equations, } \\
\text { inequalities and } \\
\text { systems; } \\
\text { expanding } \\
\text { polynomials }\end{array}$ & $\begin{array}{l}\text { Algebraic (usual) } \\
\text { Textual (action } \\
\text { menu) }\end{array}$ & $\begin{array}{l}\text { Selecting } \\
\text { alg.expressions } \\
\text { Choosing a rule } \\
\text { from a menu } \\
\text { Entering alg. } \\
\text { expressions } \\
\end{array}$ & $\begin{array}{l}\text { Formal exercises } \\
\text { (solve equations, } \\
\text { inequalities or systems } \\
\text { of equations; expand } \\
\text { polynomials) }\end{array}$ \\
\hline Aplusix & $13-16$ & $\begin{array}{l}\text { Numerical } \\
\text { calculation } \\
\text { Expanding } \\
\text { Factoring } \\
\text { Solving } \\
\text { (in)equations, } \\
\text { and systems } \\
\end{array}$ & $\begin{array}{l}\text { Algebraic (usual) } \\
\text { Tree }\end{array}$ & $\begin{array}{l}\text { On algebraic } \\
\text { expressions }\end{array}$ & $\begin{array}{l}\text { Formal exercises } \\
\text { (calculate, factor, } \\
\text { expand and simplify, } \\
\text { solve (in)equations, } \\
\text { isystems) } \\
\text { Word problems }\end{array}$ \\
\hline $\begin{array}{l}\text { AriLab2: } \\
\text { Symbolic } \\
\text { manip. }\end{array}$ & $6-12$ & $\begin{array}{l}\text { Linear } \\
\text { expressions, } \\
\text { rational } \\
\text { expressions } \\
\text { leading to deg. } 2\end{array}$ & $\begin{array}{l}\text { Numerical, } \\
\text { algebraic (usual) }\end{array}$ & $\begin{array}{l}\text { Selecting an } \\
\text { expression, } \\
\text { choosing a rule to } \\
\text { apply from a list of } \\
\text { applicable rules }\end{array}$ & Not defined \\
\hline E-slate & $12-16$ & $\begin{array}{l}\text { Fractions of a } \\
\text { quantity } \\
\text { Ordering rational } \\
\text { numbers }\end{array}$ & $\begin{array}{l}\text { Sliders } \\
\text { Symbols in } \\
\text { LOGO } \\
\text { Graphs }\end{array}$ & $\begin{array}{l}\text { On numerical values } \\
\text { in the LOGO } \\
\text { procedure, on } \\
\text { pointers on the } \\
\text { sliders }\end{array}$ & Not defined \\
\hline
\end{tabular}




\section{Appendix 4: Use-ILE interaction features of the 10 ILES}

\begin{tabular}{|c|c|c|c|c|c|}
\hline & Feedback & Reaction to error & Hint / correct answer & Diagnosis & Customization \\
\hline $\begin{array}{l}\text { Active } \\
\text { Math }\end{array}$ & $\begin{array}{l}\text { Immediate } \\
\text { checking of } \\
\text { correctness of } \\
\text { the answer }\end{array}$ & $\begin{array}{l}\text { Explanatory note if } \\
\text { classical error } \\
\text { Input syntax help if } \\
\text { syntax error } \\
\text { Hint otherwise }\end{array}$ & $\begin{array}{l}\text { Hint messages if error } \\
\text { detected } \\
\text { Hypertext links } \\
\text { Correct answer never } \\
\text { provided }\end{array}$ & $\begin{array}{l}\text { Estimation } \\
\text { of current } \\
\text { state of } \\
\text { knowledge } \\
\text { Student's } \\
\text { profile }\end{array}$ & $\begin{array}{l}\text { Possibility to } \\
\text { create her/his } \\
\text { own book } \\
\text { tailored to } \\
\text { her/his needs }\end{array}$ \\
\hline $\begin{array}{l}\text { Animal } \\
\text { Watch }\end{array}$ & $\begin{array}{l}\text { Immediate } \\
\text { checking of } \\
\text { correctness of } \\
\text { the answer }\end{array}$ & $\begin{array}{l}\text { Hints } \\
\text { Problem can be } \\
\text { solved } \\
\text { automatically }\end{array}$ & $\begin{array}{l}\text { Hints if error } \\
\text { Correct answer } \\
\text { presented step by step } \\
\text { when a student keeps } \\
\text { doing wrong }\end{array}$ & $\begin{array}{l}\text { Monitoring } \\
\text { students' } \\
\text { progress } \\
\text { based on } \\
\text { answer }\end{array}$ & $\begin{array}{l}\text { Teachers can } \\
\text { create exercises }\end{array}$ \\
\hline $\begin{array}{l}\text { Cog. } \\
\text { Tutor }\end{array}$ & $\begin{array}{l}\text { Immediate } \\
\text { checking of } \\
\text { correctness of } \\
\text { the answer }\end{array}$ & $\begin{array}{l}\text { Wrong answer red } \\
\text { Explanatory note if } \\
\text { error matches a } \\
\text { misconception }\end{array}$ & $\begin{array}{l}\text { Help message ( } 3 \\
\text { levels) on demand } \\
\text { Eventually the right } \\
\text { answer is provided }\end{array}$ & $\begin{array}{l}\text { Based on } \\
\text { knowledge } \\
\text { tracing }\end{array}$ & No \\
\hline $\begin{array}{l}\text { Math } \\
\text { Teacher+ }\end{array}$ & $\begin{array}{l}\text { Immediate } \\
\text { check of answer, } \\
\text { of end of } \\
\text { exercise } \\
\text { Interpretation } \\
\text { proposed if } \\
\text { possible } \\
\text { ambiguity }\end{array}$ & $\begin{array}{l}\text { Erroneous answer } \\
\text { getting red } \\
\text { Alert message } \\
\text { when syntax error } \\
\text { Up to } 3 \text { mistakes, } \\
\text { the system } \\
\text { provides the } \\
\text { solution }\end{array}$ & $\begin{array}{l}\text { Guidance (on } \\
\text { demand): static } \\
\text { message with general } \\
\text { idea how to start } \\
\text { solving the pb } \\
\text { Hint (on demand): } \\
\text { dynamic help based } \\
\text { on the last answer }\end{array}$ & $\begin{array}{l}\text { Report on } \\
\text { student's } \\
\text { progress } \\
\text { available } \\
\text { on } \\
\text { demand }\end{array}$ & $\begin{array}{l}\text { Teacher can } \\
\text { choose the } \\
\text { sequence to be } \\
\text { studied and set } \\
\text { up parameters } \\
\text { to control the } \\
\text { system behavior }\end{array}$ \\
\hline $\begin{array}{l}\text { Math } \\
\text { Xpert }\end{array}$ & $\begin{array}{l}\text { List of } \\
\text { compatible } \\
\text { actions appears } \\
\text { when expr. } \\
\text { selected } \\
\text { Check of end of } \\
\text { exercise on } \\
\text { demand }\end{array}$ & $\begin{array}{l}\text { Impossible to } \\
\text { commit an error }\end{array}$ & $\begin{array}{l}\text { Hint } \\
\text { AutoFinish: the } \\
\text { problem entirely } \\
\text { solved by the system } \\
\text { AutoStep: the problem } \\
\text { is solved step by step } \\
\text { by the system }\end{array}$ & No & $\begin{array}{l}\text { Teacher can } \\
\text { create exercises }\end{array}$ \\
\hline $\begin{array}{l}\text { Mrs } \\
\text { Lindquist }\end{array}$ & \multicolumn{3}{|c|}{$\begin{array}{l}\text { Dialog form immediate feedback depending on chosen tutoring } \\
\text { strategy: solve an instance of the problem then generalize it; } \\
\text { define sub-goals and solve them; explain correct answer } \\
\text { provided by the system; scaffolding; providing correct answer }\end{array}$} & $\begin{array}{l}\text { Based on } \\
\text { model } \\
\text { tracing } \\
\text { paradigm }\end{array}$ & No \\
\hline T-algebra & $\begin{array}{l}\text { Immediate } \\
\text { feedback if } \\
\text { incorrect } \\
\text { selection of a } \\
\text { sub-expr., action } \\
\text { or result }\end{array}$ & $\begin{array}{l}\text { Error message if } \\
\text { incorrect selection } \\
\text { of sub-expr., } \\
\text { action or result } \\
\text { Wrong parts of an } \\
\text { expression red }\end{array}$ & $\begin{array}{l}\text { Hint (on demand): } \\
\text { indicate action to do } \\
\text { Autosolve (on } \\
\text { demand): problem } \\
\text { solved by the system }\end{array}$ & $\begin{array}{l}\text { Reports } \\
\text { on } \\
\text { students' } \\
\text { errors } \\
\text { (nature, } \\
\text { number) }\end{array}$ & $\begin{array}{l}\text { Teacher can } \\
\text { create lists of } \\
\text { exercises with } \\
\text { teacher software }\end{array}$ \\
\hline Aplusix & $\begin{array}{l}\text { Immediate } \\
\text { check of } \\
\text { equivalence } \\
\text { between expr., } \\
\text { in training mode } \\
\text { No feedback in } \\
\text { test mode } \\
\text { Delayed } \\
\text { feedback in self- } \\
\text { correction mode } \\
\text { On demand, } \\
\text { check of end of } \\
\text { exercise }\end{array}$ & $\begin{array}{l}\text { Syntax error } \\
\text { message when } \\
\text { syntax error } \\
\text { detected } \\
\text { Blue cross lines } \\
\text { when the last } \\
\text { expression is not } \\
\text { well-formed } \\
\text { Red cross lines } \\
\text { between non } \\
\text { equivalent } \\
\text { expressions }\end{array}$ & $\begin{array}{l}\text { No hint available } \\
\text { Correct answer } \\
\text { provided on demand }\end{array}$ & $\begin{array}{l}\text { Score } \\
\text { provided } \\
\text { for } \\
\text { exercises, } \\
\text { but not for } \\
\text { word } \\
\text { problems }\end{array}$ & $\begin{array}{l}\text { Teacher can set } \\
\text { up parameters } \\
\text { to adapt the } \\
\text { behavior of the } \\
\text { software } \\
\text { Teacher can } \\
\text { create exercises } \\
\text { and problems } \\
\text { with Aplusix } \\
\text { editor }\end{array}$ \\
\hline $\begin{array}{l}\text { AriLab2: } \\
\text { Symbolic } \\
\text { manip. }\end{array}$ & $\begin{array}{l}\text { Applicable rules } \\
\text { activated when } \\
\text { expr. selected } \\
\text { Automatic } \\
\text { transformation of } \\
\text { expr. following } \\
\text { the chosen rule }\end{array}$ & $\begin{array}{l}\text { Impossible to } \\
\text { commit an error }\end{array}$ & $\begin{array}{l}\text { No hint available } \\
\text { Correct answer is not } \\
\text { provided }\end{array}$ & No & $\begin{array}{l}\text { Teacher can } \\
\text { create exercises }\end{array}$ \\
\hline E-slate & $\begin{array}{l}\text { Immediate visual } \\
\text { feedback }\end{array}$ & $\begin{array}{l}\text { Impossible to } \\
\text { commit an error }\end{array}$ & No hint available & No & $\begin{array}{l}\text { Teacher can } \\
\text { create exercises }\end{array}$ \\
\hline
\end{tabular}




\section{Appendix 5: Technical and accessibility aspects of the 10 ILES}

\begin{tabular}{|c|c|c|c|}
\hline & Operating system & Translations & License \\
\hline $\begin{array}{l}\text { Active } \\
\text { Math }\end{array}$ & $\begin{array}{l}\text { Web (Mozilla Firefox, Internet } \\
\text { Explorer, Safari) }\end{array}$ & $\begin{array}{l}\text { English, German, Spanish, } \\
\text { Mandarin, Russian, Dutch }\end{array}$ & $\begin{array}{l}\text { German Free Software } \\
\text { License }\end{array}$ \\
\hline $\begin{array}{l}\text { Animal } \\
\text { Watch }\end{array}$ & $\begin{array}{l}\text { Windows } 95 \text { and up } \\
\text { MacOS } 8.0 \text { and up }\end{array}$ & English & Sun Microsystems, Inc. \\
\hline $\begin{array}{l}\text { Cognitive } \\
\text { Tutor }\end{array}$ & $\begin{array}{l}\text { Windows } 2000, \mathrm{XP} \\
\text { MacOS } 10.3\end{array}$ & English & Carnegie Learning \\
\hline $\begin{array}{l}\text { Math } \\
\text { Teacher+ }\end{array}$ & Windows 95 and up, NT, XP & $\begin{array}{l}\text { English, Spanish, Portuguese, } \\
\text { French, German, Swedish, } \\
\text { Turkish and Hebrew }\end{array}$ & MATH-KAL \\
\hline $\begin{array}{l}\text { Math } \\
\text { Xpert }\end{array}$ & $\begin{array}{l}\text { Windows } \\
\text { Mac using Virtual PC } \\
\text { Linux using WINE }\end{array}$ & English, French, German & $\begin{array}{l}\text { 14-days trial version } \\
\text { Stand-alone license } \\
\text { Lab license }\end{array}$ \\
\hline $\begin{array}{l}\text { Mrs } \\
\text { Lindquist }\end{array}$ & Windows, Mac & English & $\mathrm{n} / \mathrm{a}$ \\
\hline T-algebra & Windows & Estonian, English & $\mathrm{n} / \mathrm{a}$ \\
\hline Aplusix & $\begin{array}{l}\text { Windows } 95 \text { and up, NT, } \\
\text { Millenium, XP, Vista }\end{array}$ & $\begin{array}{l}\text { French, English, Italian, } \\
\text { Spanish, Portuguese, } \\
\text { Vietnamese }\end{array}$ & $\begin{array}{l}\text { Commercialized by } \\
\text { publishers in a few } \\
\text { European countries }\end{array}$ \\
\hline AriLab2 & Windows & English, Italian, Spanish & DIDA.EL S.p.A., Milano, Italy \\
\hline E-slate & Windows 98 and up, XP & Greek, English & $\begin{array}{l}\text { Free use for non-commercial } \\
\text { purposes }\end{array}$ \\
\hline
\end{tabular}

